\title{
The Bruneian record of "Borneo Amber": a regional review of fossil tree resins in the Indo-Australian Archipelago
}

\author{
László Kocsis ${ }^{1,}{ }^{*}$, Anwar Usman ${ }^{2}$, Anne-Lise Jourdan ${ }^{3}$, Syaimaa' Haji Hassan ${ }^{1}$, Nurhazwana \\ Jumat $^{1}$, Dalina Daud ${ }^{2}$, Antoninio Briguglio ${ }^{4}$, Ferry Slik ${ }^{5}$, László Rinyu ${ }^{6}$, István Futó ${ }^{6}$ \\ ${ }^{1}$ Geology Group, Faculty of Science, Universiti Brunei Darussalam, Jalan Tungku Link, Gadong \\ BE1410, Brunei Darussalam \\ ${ }^{2}$ Chemistry Department, Faculty of Science, Universiti Brunei Darussalam, Jalan Tungku Link, \\ Gadong BE1410, Brunei Darussalam \\ ${ }^{3}$ Bloomsbury Environmental Isotope Facility, University College London, Gower Street, \\ London WC1E 6BT, United Kingdom \\ ${ }^{4}$ DI.S.T.A.V. - Dipartimento di Scienze della Terra, dell'Ambiente e della Vita Università degli \\ Studi di Genova, Corso Europa, 26, I - 16132 Genova, Italy \\ ${ }^{5}$ Environmental and Life Sciences Department, Faculty of Science, Universiti Brunei \\ Darussalam, Jalan Tungku Link, Gadong BE1410, Brunei Darussalam \\ ${ }^{5}$ Isotope Climatology and Environmental Research Centre (ICER), Institute for Nuclear \\ Research, Hungarian Academy of Sciences, Debrecen, Hungary
}

* Corresponding author:

Dr. László Kocsis - emails: laszlo.kocsis@ubd.edu.bn, laszlokocsis@hotmail.com

\section{Abstract}

In this study we intend to provide an overview on fossilized tree resins (amber) commonly found in Southeast Asia, more particularly in the Indo-Australian Archipelago (IAA). These remains are often referred in literature as "Indonesian amber", "Borneo amber" or simply as "dammar". They are very common in the region and the Brunei Sultanate is no exception as most of its Neogene sedimentary successions contain amber-rich layers. Although amber is a common fossil in the country and in northern Borneo, to our knowledge it has not been studied in great detail so far. Here we present an account on the "Borneo Ambers" from Brunei, regarding their stratigraphic origin, basic physical properties, their interaction with the biosphere and their botanical origin using Fourier-transform infrared spectroscopy (FTIR). Additionally, a number of ambers and modern tree resins were analysed for their carbon isotope composition and a few were tested with gas chromatography. We discuss the results in a regional and global context, in comparison with available data from the IAA.

The ambers come from four different lithostratigraphic units with an age range of 12 to 3 million years (middle Miocene to Pliocene). Recently reworked ambers from the coast, 
ambers from younger alluvial deposits, and several modern tree resins from Dipterocarpaceae and Araucariaceae (Agathis borneensis) were also included in the study. The more than 60 FTIR analyses of modern and fossil specimens suggest that all the Brunei ambers were produced by trees of Dipterocarpaceae. There is no indication of Agathis in the fossil record, in agreement with their lower abundance in the forests of Borneo. Modern and fossil dipterocarp resins were found to be different based on the following criteria: (1) Different reactions to solubility, hot needle and UV tests with faster reaction time and less fluorescence for the modern ones; (2) Clear distinction based on certain FTIR absorbance band ratios, mostly by those that represent carboxylic acids and esters (e.g., 1700 and 1243 $\mathrm{cm}^{-1}$ ); (3) Modern resin yielded on an average $3 \%$ lower $\delta^{13} \mathrm{C}$ values, (4) Gas chromatography data reflect maturation differences among the samples. Although there is some overlap in the chemical results between the two groups, generally all these differences reflect different maturation stages of the resinous material and point towards loss of low $\delta^{13} \mathrm{C}$ components from the organic structure of the resin. The minor timewise decreasing trend in average $\delta^{13} \mathrm{C}$ from the late middle Miocene to late Miocene can be explained by (1) gradual changes in local environmental conditions, and/or (2) increased amount of less mature specimens among the younger samples. In contrast, the highest obtained $\delta^{13} \mathrm{C}$ values were found in the youngest Pliocene ambers. Instead of maturation bias this can be linked to environmental factors such as cooler-drier climate with increased seasonality, probably reflecting the onset of the northern hemisphere glaciation.

Keywords: amber; resin; dipterocarp; Agathis; infrared spectroscopy; organic carbon isotopes.

\section{Introduction}

Fossil tree resins are common remains in Brunei's Neogene sediments, but they are only occasionally mentioned in geological reports (Wilford, 1961, Tate, 1973); and to our knowledge no detailed geological study has been carried out before. However, fossil tree resins referred as "Indonesian amber" or "Borneo amber" have been extensively studied and described from Southeast Asia, especially from the islands of the Indo-Australian Archipelago (IAA) (e.g., Hillmer et al., 1992; Schlee et al., 1992; Unjah et al., 2003; Lambert 
et al., 2013). In fact, the largest ever discovered amber comes from the island of Borneo, more precisely from the Merit-Pila coal mine of Sarawak (Malaysia) that had a weight of 68 kg (Langenheim, 2003).

The origin of these resins in most cases has been linked to the family Dipterocarpaceae (e.g., Langenheim and Beck, 1965; Brackman et al., 1984; Hillmer et al., 1992), a group of angiosperm tree with 16 genera that has its greatest biodiversity on Borneo (Fig. 1). The most prominent resin-producing genera are Shorea, Hopea, Dipterocarpus, Vatica, and Anisoptrea (Langenheim, 2003). The modern resin, locally called "dammar", "damar" or "damar gum", is used mainly for varnish and incense. It should be mentioned that resin and gum are used interchangeably for plant exudates, commercially and in the common language. However, as a scientific definition, the primary components of resins are volatile and non-volatile terpenoids and, in a few cases, phenols, which all are soluble in organic solvent, while gum is a water-solvable polysaccharide produced, for example, by some fruit trees of the family Rosaceae (Langenheim, 2003).

During fossilization, the tree resins go through a maturation process losing some of their volatiles and combining their monomers to more complex structures (i.e., polymerization). In the dipterocarp resin, cadinene and related isomers are the major components (Langenheim, 2003), but more thorough studies on the macromolecular structure are however necessary (Anderson and Muntean, 2000). The polymerization process starts as soon as the resin is exposed to air and sunlight, but when the resin is buried and subjected to higher temperature and pressure, the maturation is further enhanced (Langenheim, 2003). Fossilized tree resins are commonly called amber or resinite, referring respectively to macro and micro remains (Anderson, 1996). However, several other names (e.g., copal) are used in the literature, while still debating the nomenclature related to the age and maturation state of the resin (e.g., Vávra, 2009). In this study, the terminology of Anderson (1996) is used and tree resin older than $40 \mathrm{ka}$ is considered as fossil and named an "amber" or "resinite". The dipterocarp ambers are classified as Class II (polycadinene) fossil resins (sensu Anderson et al., 1992). Interestingly, some dipterocarp ambers from the IAA appear also in the literature and in museum collections under the mineral name "glessite" (Kosmowska-Ceranowicz, 2015; Vávra, 2015).

The age of the IAA dipterocarp ambers is mainly Neogene, but resin-producing trees continuously keep adding to the sedimentary record. However, the oldest records of 
dipterocarp ambers are reported from the early Eocene of India (Dutta et al., 2009; Rust et al., 2010) and the late Eocene Na Duong lignite from northern Vietnam (Böhme et al., 2013).

Both modern resin and amber from the IAA have been investigated by various methods for characterizing their components. The first infra-red spectra comparing a modern dipterocarp resin with a Sumatra amber was reported by Langenheim and Beck (1965), and the obtained similar results were related to the botanical origin of the amber. A more comprehensive organic chemistry study was later performed on a Bukit Asam amber from Sumatra, providing further evidence for a dipterocarp origin of these fossils (Brackman et al., 1984). The first chemical characterization of a Borneo amber, in fact a Bruneian specimen, was published by Van Aarseen et al. (1990), and comparison with dammar (i.e., modern dipterocarp resin) showed that these resins could have provided the cadinene source in crude oils of the region. Ambers from the Miocene Merit-Pila lignite mine (Sarawak, Malaysia) were also examined and reported to contain tri-terpenes and sesqui-terpenes, which were again linked to a dipterocarp origin (Hillmer et al. 1992). Later, the contribution of dipterocarp resins to oil formation was further shown by Murray et al (1994a) in a broader study in IAA localities, and by Stout (1995) focusing on sites in the Mahakam Delta in Kalimantan (Indonesian part of Borneo). At the same time, the first stable isotope analyses from dipterocarp ambers were conducted by Murray et al. (1994b), together with a detailed description of the organic chemistry of a Brunei specimen. This was followed by other works, including $\delta^{13} \mathrm{C}$ compositions of both modern and fossil resins from Borneo, undertaken by Stout (1995) and Murray et al. (1998).

Borneo ambers also appear in studies comparing and characterizing different types of ambers using a variety of techniques (e.g., FT-Raman: Brody et al., 2001; FTIR: KosmowskaCeranowicz, 2015; organic chemistry: Havelcová et al., 2014; stable isotopes: Tapper et al., 2013). More focused studies on "Indonesian amber" from several lignite mines in the IAA (e.g., Borneo, Sumatra, Sulawesi, Papua New Guinea) using nuclear magnetic resonance further revealed the widespread dipterocarp origin of these resins in the Southeast Asian region (Lambert et al., 2013). More recently, Kosmoswska-Ceranowicz et al. (2017) associated enhanced resin production to volcanic activity, based on investigation on ambers from Sumatra and Borneo.

The fossil content of the Borneo ambers is much less studied than their famous counterparts of the Baltic, Dominican, or Myanmar ambers. Lists of various groups of small 
arthropods entrapped in amber were reported from Miocene deposits in Sarawak (Hillmer et al., 1992) and Sabah (Hutchinson, 2005), Malaysia, but detailed taxonomical work is still rare. We only came across one detailed description of a new ant species found in the MeritPila ambers of Sarawak (de Andrade and Baroni, 2004).

Besides dipterocarps, there is another important resin-producing tree in Borneo, belonging to the gymnosperm genus Agathis, within the family Araucariaceae. In the Late Cretaceous and early Paleogene this genus was more widespread, but currently it is restricted to Southeast Asia, Australia, and New Zealand (de Laubenfels, 1988; Poinar, 1991; Farjon and Filer, 2013). The modern Agathis resin is commonly called "kauri", "kauri gum", "Manila copal", or sometimes also "dammar" to add to the confusion with dipterocarp resin. The Agathis resin is characterized by mono-terpenes in the volatile fraction and di-terpenes in the non-volatile fraction, and when it is fossilized, labdane polymers are formed dominantly (Langenheim, 2003). The compositional differences between Agathis and dipterocarps result in different physical properties (e.g., the kauri resin is harder than the dipterocarp dammar), and they can also be distinguished by spectral analyses. Based on their chemical differences, the Agathis derived resins belong to Class Ib, contrasting with Class II for dipterocarp resins (see Anderson et al., 1992). The geological record of Agathis related amber is well-documented since the Eocene in New Zealand and Australia (Lyons et al., 2009; Seyfullah et al., 2015), and Agathis is still present in these regions nowadays. However, the Early Cretaceous amber in Myanmar, from which many exceptional fossils have been described (e.g., Grimaldi et al., 2002; Ross et al., 2010; Zheng et al., 2018), were apparently also produced by Araucariaceae and possibly some close relatives of Agathis (Poinar et al., 2007). Interestingly, so far no Agathis derived ambers has been reported from the IAA, even though they are commonly found in the region today (de Laubenfels, 1988; Farjon and Filer, 2013).

Here, we present an account on the "Borneo Amber" from Brunei Darussalam, including their stratigraphic origin, age distribution, basic physical properties, appearance, and interaction with the biosphere (e.g., bioerosion, entrapped fossils). Several specimens are tested with FTIR (Fourier-transform infrared spectroscopy) together with many modern specimens from dipterocarps and an Agathis borneensis to distinguish their botanical origin (Fig. 1). Many of the fossil and modern samples were also analyzed for their stable carbon isotopic composition, while a few preliminary gas chromatograph measurements were 
carried out as well. The obtained results were then compared and discussed in a regional context of resin-producing floras in the IAA.

\section{Geological context and origin of the samples}

The geology of Brunei has been extensively studied and described in the past in relation to the neighbouring regions of N-NW Borneo (Liechti, 1960; Wilford, 1961; Sandal, 1996; Hutchinson, 2005). The rocks in Brunei have a mostly siliciclastic sedimentary origin, and have been deposited since the early Miocene with regional unconformities recognized along the successions (e.g., Kessler and Jong, 2015). The rocks are partly deformed due to many largescale N-S and NE-SW trending synclines (Berakas, Belait, Badas) and anticlines (Jerudong, Belait) (Sandal, 1996). In the hinterland south of Brunei, the Crocker Range (Rajang Group) emerges. This is a former accretionary prism now metamorphosed and strongly folded (with an average today's height of $1800 \mathrm{~m}$ ), which got eroded and shed sediments into the Neogene basins of northwest Borneo. These sediments were carried downslope via several relatively short but highly efficient rivers forming multiple deltaic systems along the coast line (e.g., Lambiasie and Cullen, 2013; Collins et al., 2017). In the view of eustatic sea-level changes, local tectonics (subsidence vs. uplift), and the amount of sediment supply, the paleoenvironment varied both spatially and temporally and the following major depositional settings have been recognized in Brunei (Liechti, 1960; Wilford, 1961; Sandal, 1996): (1) deeper mudstone-dominated offshore facies (Setap Shale Formation); (2) coastal shallow-marine facies with several parasequences (Miri and Seria Fm.); (3) sand-rich wave- and tide-dominated deltaic facies (Belait and Lambir Fm.); and (4) dominantly fluvial and lagoon facies (Liang Fm.). The onshore lithology of some of these rock formations is quite similar and Liechti (1960: 186 p.) mentioned that the Lambir, Miri and Seria formations would preferably be members of the Belait Formation; nevertheless, here the formation nomenclature is followed (Fig. 2). In some of these formations (e.g., Belait and Liang Fm.), lignite deposits often occur, but organic matter enrichment can be seen in some layers in almost all lithostratigraphic units. Amber and resinite are frequently found especially in these organic-rich levels.

\subsection{Fossil samples}


In four of the lithostratigraphic units detailed below, fossil resins are often found and many different outcrops have been sampled. In some cases, several amber-rich levels have also been recorded along sedimentary profiles. For details, refer to Figure 2 and Table 1 . For the exact geographic coordinates see Supplementary Material 1.

Belait Formation: It consists mainly of an alternation of sandstones, siltstone, and claystone in varying proportion and thickness. The paleoenvironment was dominantly an alternation between deltaic and coastal marine facies (Lambiase and Cullen, 2013). The age of these beds is early to late Miocene. The oldest amber samples were collected from this lithostratigraphic unit from the south and southwest part of the Berakas syncline (Mentiri, Subok, Sungai Akar, Kpg. Rimba), and somewhat younger specimens from the western flank of the Jerudong anticline (H84, Water Tower).

Miri Formation: Similar to the Belait Fm. but with thicker dominantly marine clay intervals at the base of parasequences, which often contain well-preserved marine calcareous fossils (Wilford, 1961). It is deposited mainly in coastal marine settings, frequently with storminitiated beds of upper-lower shoreface facies (Collins et al., 2017). It interfingers with the top part of the Belait Fm. in the region. The age of the deposits in Brunei is latest middle Miocene to late Miocene. Ambers can often be found in both sand- and clay-rich horizons. Six sites are involved from the western flank of the Jerudong anticline along the Tutong Road (Tanjong Nangka, Jalan Kecil Paya, Jalan Tutong 2 and 3, Ikas Bandung, Maraburong). Additionally, samples were collected from the "105 Sand" at the Hospital Road outcrop in Miri, Sarawak (Malaysia), which unit has an older stratigraphic position compared to the investigated beds of the Miri Formation in Brunei (see Wannier et al., 2011).

Seria Formation: Younger than the Miri Fm., with less consolidated sand-, silt- and claystone, but the depositional environment was quite similar. Ambers in these rocks can be found almost everywhere, but they are most common at the base of parasequences. We studied ambers from six outcrops (i.e., Green House, Keriam, Ambug Hill, Jalan Pak Bidang 1 and 2, Jalan Rumpau Rambai), with the Ambug Hill near Tutong town yielding several samples. At this late Miocene site, four sedimentary units are distinguished (Kocsis et al., 2018a), which have been intensively studied due to their rich marine fossil content (Harzhauser et al., 2018; Kocsis et al., 2018b; Rosilm et al., 2019).

Liang Formation: The youngest lithostratigraphic unit that covers the Seria and Belait formations in the coastal areas with the two members Berakas and Lumut. The depositional 
environment was a dominantly tide-influenced lagoonal setting in the Lumut area and tidal and braided river deposits in the Berakas area (Wannier et al., 2011). The age of these deposits is latest Miocene - Pliocene (Sandal, 1996). Ambers were collected in the Berakas Forest Reserve from three different outcrops.

Additional samples: A few specimens were collected from younger deposits such as from (1) white, leached sand that covers the Liang Fm. in the Lumut area (Sungai Paku), with a likely age of Pleistocene, although the ambers found there are most possibly reworked from older beds, and (2) washed-up ambers were collected on the Muara and Penanjong beaches, where respective layers of the Belait and Seria formations cross the coast line.

\subsection{Modern samples}

Several modern resin samples were collected from dipterocarp-dominated forests (Fig. 1) where the resins were either found in clumps on the forest floor (Andulau Forest Reserve) or obtained from fallen, partly buried tree trunks (Teraja, Badas). Large resin pieces were discovered in the soil covering the sand ridges of the Belait Fm. in the Tasek Lama Recreational Park in the southern part of the Belait syncline (TL). Direct sampling of dipterocarp trees was done in the Ulu ulu National Park in Temburong, and from an Agathis borneensis in the forest at the campus of the Universiti Brunei Darussalam. Furthermore, dipterocarp resin was collected in Sabah, Malaysia, in the Sunbear conservation centre in Sepilok from Shorea xanthophylla. One gum sample produced by a lime tree in Brunei was also obtained (Fig. 1c).

\section{Material and methods}

Several hundreds of ambers have been collected from the above-mentioned formations during the last few years (Figs 3-4). Some localities have been visited more often due to ongoing research projects (e.g., Ambug Hill quarry (AH), Tanjong Nankga (JT1) or the Subok (Sub) sites), which allowed several different sedimentary layers to be sampled. From other localities, only certain beds yielded large amounts of ambers, of which one clay layer at the Sungai Akar (SA) outcrop or the silty-sandy base of the fossil-rich site at Jalan Pak Bidang (JPB1). Regarding modern/sub-modern tree resins, many specimens were collected from soil that covers sandstone ridges at the Tasek Lama Park (TL). For more details on these and other sites see Figures 1-2 and Table 1. 
The studied samples were documented regarding their origin, preservation, and physical properties (see Figs 3-6). Transparent specimens were checked for fossil content with transmitted light using RaxVision stereomicroscopes.

\subsection{C-14 dating}

Some samples were screened with the radiocarbon method using a gas proportional counting system (GPC) at the Isotope Climatology and Environmental Research Center of the Institute for Nuclear Research (Atomki) of the Hungarian Academy of Sciences. Resins collected from the forest floor (AFR) and soils (TL) were the main target, but old amber (Sub) and a fossil wood from Ambug Hill were also tested. A modern cherry tree gum from Hungary was run as a base line. All samples were pre-treated in the same way. Five minutes of ultrasonic bath cleaning in ethanol was the first step. Subsequently, in order to remove the remaining ethanol, three times five minutes of ultrasonic bath cleaning was performed in ultra-pure, carbon-free ion-exchanged water. Before grinding the samples for the combustion, they were dried in a $60{ }^{\circ} \mathrm{C}$ oven until the weight balance was reached. The combustion process was carried out on a specially developed converter and chromatographic gas cleaning line (Csongor et al., 1982). The radiocarbon content of the cleaned carbon dioxide was measured on a low-level, high-precision proportional counter system (Hertelendi et al., 1989). The counter system was designed and built in Atomki. $\mathrm{CO}_{2}$ gas prepared from NIST-SRM-4990c oxalic acid standard (134.07 pMC - present modern carbon, $\delta^{13} \mathrm{C}=-17.78 \pm 0.08 \%$ ) was used as normalization standard, and fossil radiocarbonfree $\mathrm{CO}_{2}$ gas (Linde $\mathrm{AG}$, Répcelak, Hungary, 4.5 purity, $\delta^{13} \mathrm{C}=-3.78 \pm 0.08 \%$ ) was used to determine the background level of the system. A $10 \mathrm{ml}$ gas sample was taken from each sample for ${ }^{13} \mathrm{C} /{ }^{12} \mathrm{C}$ isotope ratio measurement in order to correct the radiocarbon results against isotope fractionation.

\subsection{Physical and chemical tests}

A subset of twelve samples including a Baltic amber specimen collected on a Lithuanian beach in 2010 was subjected to a few simple physical and chemical tests in order to check and compare their maturity (Poinar, 1992): (1) Heat needle test - a way to determine relative hardness and melting points; (2) Odour of freshly broken samples followed by the heat test; (3) UV-light fluorescence - more mature samples have typical blue shade 
fluorescence; (4) Flotation test in local seawater - indication for specific gravity: generally amber and resin have a specific gravity close to one, thus they often float in seawater; (5) Acetone tests - solubility: a) submerged for 5 mins and b) left in solution overnight - the more mature the sample the less reaction is expected.

\subsection{Fourier-transform infrared spectroscopy (FTIR)}

A larger sample set with 48 Borneo amber specimens was prepared for IR spectral analyses in order to obtain characteristic fingerprints indicative of the possible plant group that produced the resins. Additionally, 7 modern resins from dipterocarp forests, three of unknown origin of modern/sub-modern resin derived from soil (TL), and one from Agathis borneensis were prepared. Two samples Ter and TL1-2, a tree bark and a soil-derived sample, respectively, were sub-sampled in their interior fresh part and their external rather weathered surface. Altogether 61 samples were powdered, using an agate mortar, and then about $2 \mathrm{mg}$ were mixed with $200 \mathrm{mg}$ potassium bromide ( $\mathrm{KBr})$. The mixture was inserted in the hydraulic press to form pellets, which were then analyzed on a Shimadzu IRPestrige-21 machine with IR Solution 1.50 (version 2008) software at the Chemistry Department of Faculty of Science, Universiti Brunei Darussalam. For some samples, repeated analyses were done with a higher (up to 7-8 $\mathrm{mg}$ ) resin portion in the $\mathrm{KBr}$ mixture. Absorbance data was collected in the range of 4000 to $500 \mathrm{~cm}^{-1}$ with a resolution of $2 \mathrm{~cm}^{-1}$. To compare the data, all the spectra were normalized to the highest absorbance peak, and some selected ones are presented in Figures 7-8. The main absorbance peaks are listed in Table 2.

\subsection{Gas Chromatography Mass Spectrometry (GC-MS)}

A few modern resins and ambers of different ages were grounded using an agate mortar and blended into small particles with the sizes of 0.2-1 mm. Each amber powder (30 $\mathrm{mg}$ ) was soaked in $30 \mathrm{~mL}$ of HPLC grade methanol while stirring for 1 hour at room temperature. The colloids were then filtered off and the supernatants were centrifuged at $3000 \mathrm{rpm}$ for 5 minutes to remove the particulates. They were then put in GC-MS vials and immediately subjected to GC-MS experiments. A Shimadzu GC/MS-QP2010 system equipped with a split/split less injector was utilized to characterize the compounds in the methanolic extracts of the different amber samples. The separation of the compounds was performed on a DB-5 ms column (length $30 \mathrm{~m}$, diameter $0.25 \mathrm{~mm}$, and thickness $0.25-\mu \mathrm{m}$ film). Helium was used 
as the carrier gas at a constant flow of $1.69 \mathrm{~mL} / \mathrm{min}$, at a flow rate of $1.00 \mathrm{ml} / \mathrm{min}$ and a split ratio of 100.0 . The oven temperature was programmed on heating from 50 to $140^{\circ} \mathrm{C}$ at a rate of $20^{\circ} \mathrm{C} / \mathrm{min}$. The temperature was then increased stepwise from 140 to $250^{\circ} \mathrm{C}$ at a rate of $10^{\circ} \mathrm{C} / \mathrm{min}$ and held at this final temperature for $10 \mathrm{~min}$. Helium was used as the carrier gas at a constant flow of $1.69 \mathrm{~mL} / \mathrm{min}$. The mass-selective detector was set at capillary direct interface temperature of $200^{\circ} \mathrm{C}$, ionization energy of $70 \mathrm{eV}$, and full scan mode with a mass range of $2-500 \mathrm{~m} / \mathrm{z}$. The compounds in the amber extracts were identified by comparing their retention time and mass spectra with those of reported compounds in the NIST 2008 version database and published literature data. Between the samples, several HPLC grade methanol was used as the blank.

\subsection{Stable carbon isotope analyses}

Thirty-three amber samples and nine modern resins (eight from Dipterocarpacea and one from Agathis borneensis), were analysed for $\delta^{13} \mathrm{C}_{\text {org }}$ using a Flash EA 1112 and a Delta V gassource isotope ratio mass spectrometer (Thermo ${ }^{\circledR}$ ) at the Bloomsbury Environmental Isotope Facility of the University College London. Bulk dry powdered samples (about 60 to 100 micrograms) were loaded into tin capsules that were placed into an autosampler and dropped into a furnace held at $1020^{\circ} \mathrm{C}$, where they were burned with a pulse of oxygen at about $1800^{\circ} \mathrm{C}$. The gases released were carried by He through an oxidant (Chromium oxide) to complete the burning, followed by chemical traps (Silver cobalt) to trap sulphur and halogens, a copper reduction furnace to trap excess $\mathrm{O}_{2}$, a drying tube (magnesium perchlorate) to remove possible water contamination, and finally a GC column to separate the different gases ( $\mathrm{N}_{2}$ from $\mathrm{CO}_{2}$ for example) before flowing to the EA detector and finally into the mass spectrometer via a CONFLO IV interface. The results were calibrated against international (i.e. ANU, IAEA-CH3, USGS40, USGS24) and working laboratory (i.e. caffeine, corn flour, and graphite) standards. Carbon isotope ratios are reported in the conventional $\delta$-notation with respect to the V-PDB (Pee Dee Belemnite) carbonate standard.

\section{Results}

\subsection{C-14 dating}


The AFR-1 forest floor resin from Brunei yielded 104 pMC confirming the expected modern origin of the sample (see Supplementary Material 2). The two samples that derived from soil yielded 73 and 93 pMC, which correspond to around 2480 and 545 BP years, respectively, in conventional radiocarbon ages. After calibration with the Calib 7.1 radiocarbon calibration program (Stuvier et al., 1993, Reimer et al., 2013), the calibrated calendar age interval of TL1-1 is 775-472 BC, while for TL1-2 it is 1391-1430 AD. The Subok amber (Sub-1) and the fossil wood from Ambug Hill contained no C-14.

\subsection{Physical and chemical tests}

Twelve samples have been tested with simple methods (see Supplementary Material 3) and a selection of those is shown in Figure 6. All the Borneo samples ( 9 ambers and 2 resins) melted easily when touched with the hot needle and all of them emitted white smoke. The two modern samples and one of the fossil samples ( $\mathrm{AH}-3)$ reacted faster. In contrast, the Baltic amber reacted less easily and no smoke was observable, although a resinous odour was detected. All the samples have a natural resinous, sweet odour when freshly broken except for the Baltic amber. After reacting with the hot needle, the resinous smell was dominant, but more acrid ( $\mathrm{AH}-3)$ and lemony tinges (modern resins) were also produced.

All samples show bluish fluorescence on freshly broken surfaces under UV-light. Weathered or external surfaces have no or far less intensity. The modern resins clearly display less fluorescence, while some of the Miocene samples yielded very intense blue colour (Fig. 6).

The samples were submerged in locally collected seawater from the South-China Sea. Only four out of the twelve samples floated on the surface. Samples having woody remains (TL1-2) or obvious bubble inclusions (Amb-2) were the ones which floated easily.

To test for solubility, the samples were shortly submerged in acetone. After 5 minutes the liquid phase turned to yellowish for two samples (Amb-2 and TL1-2), while the surface of the Pliocene Ber-1 and the modern BM-1 samples turned white. After overnight submersion, all samples had their surface affected by acetone, except for the Baltic amber. The two modern samples (BM-1 and TL1-2) disintegrated.

\subsection{Fourier-transform infrared spectroscopy (FTIR)}


All the fossil and most of the modern samples from Brunei yielded very similar FTIR spectra, which were clearly different from the sample of $A$. borneensis (Fig. 7). The exact position of the maximum absorbance bands varied somewhat among the samples with different variability along the spectrum (see Table 2). The largest absorbance bands are in the symmetric and asymmetric C-H vibrations range between 2959 and $2929 \mathrm{~cm}^{-1}$, where a double peak is observable (averages at 2957 and $2931 \mathrm{~cm}^{-1}$ ), which is followed by the third largest peak at $2931 \mathrm{~cm}^{-1}$.

In the vibration range of double bond $\mathrm{C}=\mathrm{C}$ and $\mathrm{O}=\mathrm{O}$ (see Fig. 7) the average maximum is at $1700 \mathrm{~cm}^{-1}$, but with some variability among the samples (Table 2) for both modern and fossil. Small absorbance bands may occur also at $\sim 1730$ and $\sim 1654 \mathrm{~cm}^{-1}$ wavenumbers for certain samples. In case of the Agathis sample, the overall highest absorbance band appears in the spectral range at $1692 \mathrm{~cm}^{-1}$ and shows a clearly visible secondary absorbance band at $\sim 1645 \mathrm{~cm}^{-1}$.

In the region of single bonds and skeletal vibrations of $\mathrm{C}-\mathrm{O}$ and $\mathrm{C}-\mathrm{C}$, the largest absorbance bands appear at an average of $1460 \mathrm{~cm}^{-1}$, followed by a band at $1384 \mathrm{~cm}^{-1}$. The smaller peak actually shows a triplet band series when zoomed in (Fig. 7a), which does not appear for the conifer sample. The subsequent absorbance bands of the spectra are much smaller in the Borneo samples, but not in the cases of the Agathis sample, and the range of $1400-1000 \mathrm{~cm}^{-1}$ is where the most obvious differences appear. However, some variability can still be detected among the Borneo samples, especially between the modern and fossil samples where some of the key bands are at 1243, 1180, and $1161 \mathrm{~cm}^{-1}$. Principal Component Analyses (PCA) was performed using 18 characteristic FTIR spectra (Table 2) of the 60 dipterocarp resins where the first two eigenvalues explain more than $78 \%$ of the variance among the samples, and the result indicate further differences between modern and fossil resins (Fig. 7b). To emphasize these differences, selected band ratios were plotted in Figure 8. These are 1700/1460 versus 1384/1243, and 1161/1180 versus $1384 / 1046 \mathrm{~cm}^{-1}$. Note that the maxima around these bands were derived from the individual samples to calculate the ratios (Table 2). Samples from the Miocene formations are put together as there is no significant difference between them. The Pliocene (3), reworked (3), and modern (12) samples are plotted separately. Only a few Miocene samples overlap with the modern ones, while the three Pliocene samples (Ber) plot somewhat closer to the modern resins. 
For two samples (TL1-2 and Ter), the weathered external surface was analysed as well. In case of Ter no major differences appeared in the spectra, however the external part of TL1-2 yielded a somewhat different FTIR spectrum (Fig. 8). Generally, the $1700 \mathrm{~cm}^{-1}$ band is wider and larger than any following peak, and the background absorbance is higher in the range of $1400-1000 \mathrm{~cm}^{-1}$, with less individual bands visible (Fig. 8).

\subsection{Gas Chromatography Mass Spectrometry (GC-MS)}

Altogether eight samples were subjected to gas-chromatograph analyses: two modern (Bad, ARF1a), one sub-modern (TL1-2int), and five fossil tree resins (Ber3, Amb2, H84-2, JT13, Sub3) ranging from Pliocene to middle Miocene in age (see Table 1 and Fig. 2). It must be noted that in this study the GC was performed on methanolic extracts of the samples, thus, due to the strong polarity of methanol, the compounds extracted and detected in GC-MS measurements are semi-polar. This is in contrast to GC-MS study on modern and fossil resins in Borneo (e.g., Brackman et al., 1984; Van Aarseen et al., 1990; Stout, 1995), which were extracted in hexane and dichloromethane, where the extracted and detected compounds are much less and non-polar. Thus, it should be noted that the compounds reported here do not reproduce those extracted in hexane and dichloromethane, but as discussed below, some less polar compounds can be related to corresponding terpenes and cadenine derivatives reported earlier in the literature (e.g., Brackman et al., 1984; Van Aarseen et al., 1990; Stout, 1995).

The compounds with short retention times below 7 mins and long retention times longer than 12 mins observed in the modern resin of AFR1a were not detected in other modern samples and old fossil ones. The first are related to volatile compounds, which may already have evaporated from the other samples, whereas the latter decomposed or converted into different compounds and accumulated with time. The detected compounds in the submodern and fossil resin methanolic extracts are mainly naphthalene derivatives, cadina, cadinol, heptane, tetrahydroabietic acid, and androstanon, though with different relative compositions. These compounds are consistently detected in the fossil samples of Ber3, Amb2, JT1-3, and Sub1 (Fig. 9). One exception is the GC spectrum of the late Miocene H84-2 sample that shows a somewhat similar feature to the modern resins of Bad and TL1-2int. Even if these resins are not identical in their organic contents, they seem to retain some components that are clearly lost from most of the fossil resins during diagenesis. The fact 
that H84 still yielded such compounds indicates lower maturity compared to its fossil counterparts. Since the compounds such as dihydropyran and butenal derivatives are nonvolatile, this data may also offer an interpretation that they are the precursors of the compounds observed in the fossil samples.

\subsection{Stable carbon isotope analyses}

Thirty fossil, 3 reworked, and 9 modern samples were analysed, some in duplicate measurements (Table 3), and the results are plotted with other data from the literature in Figure 10. The overall average $\delta^{13} \mathrm{C}$ of the 29 Borneo ambers is $-27.4 \pm 1.4 \%$, with a maximum of $-25.1 \%$ and minimum of $-30.6 \%$. Breaking down to four time steps, the following averages were calculated: (1) late middle Miocene (late Serravallian) - Belait and Miri Fm.: -26.9 $\pm 0.4 \%$ \% $(n=4)$; (2) early late Miocene (Tortonian)- Belait and Miri Fm.:-27.3 $\pm 1.3 \%$ o $(n=11)$; (3) latest Miocene (late Tortonian - Messinian) - Seria Fm.: $-28.1 \pm 1.4 \%$ o ( $n=12$ ); and (4) Pliocene- Liang Fm.: -25.4 $0.2 \%$ ( $n=3$ ) (see Figs 2 and 10c). The three samples from the beach and Pleistocene sand gave an average of $-28.7 \pm 0.1 \%$ o. The modern resins have a range from -32.1 to $-26.6 \%$. The $A$. borneensis sample has the highest value, while the mean value for the dipterocarp samples is $-30.0 \pm 1.5 \%(n=8)$.

\section{Discussion}

\subsection{General appearance of the ambers}

All sediments deposited in shallow-marine, transitional, and continental environments often yield ambers in Brunei Darussalam. The ambers are frequently found in organic-rich layers, sometimes within lignite or beside fossil wood remains, but they are also commonly found simply as pebbles or fragments in sand-, silt- or clay-rich layers (Fig. 3). They are either individual specimens or attached to fossilized wood as void fillings. Their external part is often corroded or has a woody appearance (Fig. 4). Some specimens are rounded, smooth surfaced and sort of streamlined indicating abrasion during transport. The ambers come in very variable shape, size and colour. The largest specimen discovered so far in Brunei is a cobble-like, opaque specimen found at Ambug Hill. Its length is $19.5 \mathrm{~cm}$ and its maximum width is $11 \mathrm{~cm}$ (Fig. 4a). Most commonly the ambers have woody or weathered external surfaces, they are opaque with orange, yellow, and greenish coloured internal parts. Other 
commonly occurring types are translucent/transparent when broken, with the most frequent colour being orange and dark red, but black and green varieties also occur.

Many amber pieces bear large holes (Figs $4 d$-e) indicating a type of bioerosion on the already hardened tree resin. In some exceptional specimens, the entire structure of the hole and even the cast and imprint of bivalve shells can be observed (Figs $5 a-b$ ). In fact, these holes used to be the living chambers of these organisms (i.e., domichnia trace fossil), which have been identified as the genus Martesia from the family Pholadidae. This is a typical wood-boring bivalve often found in drift wood in marine and brackish environments. The recent species $M$. striata has a worldwide distribution in the tropics and subtropics, typically in the intertidal and shallow subtidal region, and it is considered as one of the most destructive marine boring organisms (e.g., Turner, 1954; Pourchon, 1956; Ansel and Nair, 1969). Besides in wood, this species also bores in a variety of other substrates such as calcareous shells, rocks of varying hardness, and even in some synthetic materials (Turner, 1954); therefore it is not surprising to find its remains and trace fossils in amber. Moreover, its presence further supports the transport of ambers in aquatic environments from their original forest source to their various final depositional sites. Bored ambers were also reported from Cape York, northern Australia (Colchester et al., 2006); however, "shipworms" (Teredo sp.) were suggested to create those holes. On the contrary, martesiins bivalves from the Cretaceous Myanmar amber seem to be similar to those here presented. The interesting fact for these old remains is that some bivalves were trapped in the originally still soft resin, while others drilled in hardened specimens (Smith and Ross, 2018).

Other fascinating observations are in the amber found at the PT site with an oyster growing on its surface (Fig. 5c), and one pebble-sized Miri amber that shows encrustation of bryozoans on its exterior (Fig. 5d). Both these cases further evidence that some ambers were transported and deposited into shallow-marine environments after solidification of the resin and could have been reworked a few times along the paleo-coast line.

Other ambers preserved fossils when the resin was still soft. A unique specimen was found with a leaf imprint that, based on its shape and venation pattern, strongly resembles a Shorea sp. or Hopea sp., both from the dipterocarp family (Fig. 5e). Additionally, a few ambers, especially from the Subok sites (late middle Miocene) yielded insect inclusions, some of which resemble ants (Figs $5 f-h$ ). So far only few localities from Borneo have ambers that contain arthropod remains. The Merit-Pila coal pit in Sarawak yielded small $(2-5 \mathrm{~mm})$ 
specimens, and Hillmer et al. (1992) listed a fauna inventory with centipede, spider, and at least 15 insect taxa and illustrated a small beetle fossil. As far as we know, only one detailed taxonomic study has been conducted, which described a new ant species (Cataulacus plebeius, see de Andrade and Baroni, 2004). Furthermore, the presence of spiders, millipedes, ants, and other insects were also mentioned from ambers of the upper Miocene Sandakan Formation and the lower-middle Miocene Tanjong Formation in Sabah, Malaysia (Hutchinson, 2005: pages 278 and 288). In Brunei, besides insects, also sediment grains, soil, and pollen have been observed from time to time in the ambers. Research on the entrapped fossils is still in progress and we expect to get a better insight on such remains in the near future.

\subsection{FTIR spectra and the botanical source of the ambers}

The similarities in the FTIR spectra between the fossil and modern tree resins can be associated with a similar botanical source, in this case the dipterocarp family. Analogous FTIR spectra were also reported from Miocene ambers and modern dipterocarp resins in the IAA (Langenheim and Beck, 1965; Tappert et al., 2013; Kosmowska-Ceranowicz, 2015). The dipterocarps are present in Borneo and in Southeast Asia at least since the Oligocene based on reported pollen fossils (Muller, 1981), and they are the dominant tree group and resin producers in the region today (Langenheim, 2003). Therefore, relating the ambers' botanical source to dipterocarps seems reasonable. The possible recovered dipterocarp leaf imprint in one of our amber samples (Fig. 5e) forms additional indirect evidence. Nuclear Magnetic Resonance (NMR) characterization of ambers from a wider geographic range in Indonesia came to the same conclusion of a dipterocarp origin of the IAA ambers (Lambert et al., 2013).

The FTIR spectra reported from the oldest dipterocarp amber from Eocene lignite beds in India (Cambay amber - Dutta et al., 2009) are also comparable with our Borneo data. In India, the anatomy of wood remains and pollen also support a Dipterocarpaceae origin (Rust et al., 2010; Dutta et al., 2011). In contrast, the Na Duong fossil resins in Vietnam (Böhme et al., 2013), although they have similar spectra and are interpreted as dipterocarps, they miss some absorbance bands compared to the Bruneian ambers. The most obvious one is at 1046 $\mathrm{cm}^{-1}$ (C-O stretching - alcohol). This may relate to enhanced maturity and hence to a different thermal history. 
Ambers found on the beach at Cape Weymouth (northeastern Australia) yielded dipterocarp-type FTIR spectra as well (Colchester et al., 2006) and were later shown to be cadinene-based Class II resins (Sonibare et al., 2014) similar to the IAA ones. However, the Australian fossil record does not support the presence of dipterocarps on the continent (Morley, 2000). Dipterocarpaceae are thought to have originated in Gondwana sometimes in the Late Cretaceous and were common in India from where they most likely spread out to Asia, but not to Australia (Morley, 2000). Consequently, these fossil samples are suggested to have drifted to Australia via oceanic currents from Southeast Asia. Interestingly, ambers of dipterocarp origin were also found on the beach in southern Australia, much farther away from an IAA source, and an oceanic transport from Southeast Asia was proposed here as well (Murray et al., 1994b). However, Coward et al. (2018) reported some undoubted autochthonous Eocene resins from southern Australia that belong to Class II resin suggesting a locally available polycadinene producing botanical source, which requires further investigations.

The other expected producers of large amounts of resin in the region are the conifer araucarians (i.e., kauri resin). None of the Borneo ambers yielded any FTIR spectrum that resembles the ones of the modern $A$. borneensis or any other reported araucarians (Lyons et al., 2009; Tappert et al., 2011; Seyfullah et al., 2015). These trees occur today in Southeast Asia, Australia, and New Zealand (de Laubenfels, 1988; Farjon and Filer, 2013). Their fossil resins were reported in Myanmar (Early Cretaceous - Poinar et al., 2007), New Zealand, and Australia (Eocene and Miocene - Lyons et al., 2009; Seyfullah et al., 2015, 2018; Coward et al., 2018), but so far they seem absent from the IAA record. The possible reason for their absence may be their much lower relative abundance compared to the dipterocarps. Based on modern tree inventory databases (diameter $>10 \mathrm{~cm}$ ) in pristine forest of Borneo with more than 205 thousands inventoried trees, as much as $19.2 \%$ belong to the dipterocarps, while Agathis trees represent 0.2\% (Slik et al., 2003).

It should be mentioned that trees of the rare genus Mastixia (Nyssaceae) are known to produce some resin that is also grouped within the Class II (polycadenine) resins such as the dipterocarps (Van Aarsen et al., 1994). These trees occur scattered in mixed dipterocarp forests in Indonesia, Malaysia, and the Philippines (Langenheim, 2003). Unfortunately, there are no available FTIR spectra to compare our data with, but these trees are even less common than the Agathis (i.e., $0.1 \%$ on Borneo) (Slik et al., 2003). So far, the only 
unambiguous ambers of Nyssaceae origin were reported from resin canals of fossil fruits from Eocene localities in England and Germany (Van Aarsen et al., 1994).

\subsection{Modern versus fossilized resins}

The basic physical property tests showed that the faster reaction with the hot needle and acetone (i.e., solubility) of the modern samples supports a lower stage of maturation, and it seems that the lower UV fluorescence is also a key feature for distinguishing between modern and fossil tree resins (Fig. 6, Supplementary Material 3). Unfortunately, the floating test could not separate amber and resin due to their very similar specific gravity and the various presences of air-bubbles and woody parts in both. Interestingly, colour changes such as darkening of the ambers were suggested to reflect increased oxidation and weathering (Poinar and Mastalerz, 2000); however, this is not seen on the samples tested here.

Subtle differences along the FTIR spectra have been recognized between modern and fossil dipterocarp samples, which can be best observed on absorbance band ratios of 1700 $\mathrm{cm}^{-1} / 1460 \mathrm{~cm}^{-1}$ vs $1384 \mathrm{~cm}^{-1} / 1243 \mathrm{~cm}^{-1}$ and $1161 \mathrm{~cm}^{-1} / 1180 \mathrm{~cm}^{-1}$ vs $1384 \mathrm{~cm}^{-1} / 1046 \mathrm{~cm}^{-}$ ${ }^{1}$, which are also supported by PCA statistics (see Figs 7-8). Because there were no significant differences among average values of the different Miocene formations, they have been considered together, but the few Pliocene and the reworked samples are shown separately. The modern samples tend to have relatively higher $1700 / 1460$ and $1161 / 1180$ ratios, while lower $1384 / 1243$ and $1384 / 1046$ ratios that evidently separate them from most of the fossil samples. Only a few Miocene ambers overlap with the modern ones, and these are largely from the younger beds of the Seria (e.g., some AH samples) and Belait (e.g., WT and H84) formations. Additionally, the Pliocene (Ber) and two of the reworked samples seem to plot closer to the modern resins (Fig. 8). Even though the absolute ages of the ambers range between 12 and 3 million years, these observations are best explained by the different maturity of the samples, which links to different burial/thermal history. The most obvious differences relate to the relatively higher peaks in the modern samples at $\sim 1700 \mathrm{~cm}^{-1} \mathrm{C}=\mathrm{O}$ double bond and at $1243 \mathrm{~cm}^{-1}$ single $\mathrm{C}-\mathrm{O}$ stretching. The first can be linked to carboxylic acids/esters, while the second one mainly to esters. The intensity reduction of these absorbance bands during maturation could indicate modification of some functional groups linked mainly to triterpenoids in the resins (e.g., Brackman et al., 1984; Stout, 1995), and/or may indicate early loss of volatiles. In relation to this issue, for instance, chemical 
components having an acetate functional group contained in the resins could have slowly dissociated into quinoic compounds and volatile ethanoic acid (also called acetic acid) according to the following scheme:<smiles>CCCCC</smiles>

where $\mathrm{R}$ denotes the aromatic moiety.

The maturity change is also supported by the GC data with general differences between modern and fossil samples. However, fossil samples overlapping with modern ones in their FTIR peak also retain some organic compounds that are present in the modern resins (Fig. 9). This outcome indicates that even if some of these dipterocarp ambers come from old deposits their maturation state may not be as expected for their age. Ross (2010) mentioned that Miocene "Borneo amber" from claystone retained volatiles that otherwise were lost from sandstone-derived samples of the same age, and therefore indicate low maturity. Such a direct correlation between lithology and our data is not obvious, but the samples cluster closer to modern tree resins (Figs 7-8) come from clay-rich beds. Therefore, it seems that the depositional setting (e.g., type of lithology, sediment thickness), but probably also transport, the original size, and composition of the amber are among many variables that could have played a role in the observed variation in our results from fossil and modern tree resins.

\subsection{Carbon isotopic composition of amber}

The $\delta^{13} \mathrm{C}$ composition of amber largely depends on resin biosynthesis, environmental factors that affect the whole plant (e.g., Kohn, 2010), and diagenesis (e.g., Spiker and Hatcher, 1987). Dal Corso et al. (2017) reported a minor negative offset between liquidviscous resin and solid ones in case of conifers, while other studies mentioned amber as one of the most enriched in C-13 among all plant carbon sources (e.g., Nordt et al., 2016).

Variation among the $\delta^{13} \mathrm{C}$ values within the modern dipterocarps might be explained by environmental factors such as the lower $\delta^{13} \mathrm{C}$ values reflecting high mean annual precipitation (MAP) of the tropics and/or canopy effect (e.g., Kohn, 2010), while the higher $\delta^{13} \mathrm{C}$ may be linked to altitude effect or early stage of enhanced maturation (e.g., Kohn, 
2010; Dal Corso et al., 2017). In our study, the overall average carbon stable isotope compositions were found to be different for resins and ambers. Extending our database with data found in the literature (Murray et al., 1994b, 1998; Stout, 1995), the fossil samples show a more than $3 \%$ higher average value when compared to the modern ones (Fig. 10a). The $-27.4 \pm 1.4 \%$ o $(n=35)$ mean fossil value is also very similar to other reported average dipterocarp data from the Miocene $(-26.1 \pm 0.3 \%, n=12)$ and Eocene $(-25.8 \pm 0.8 \%, n=10)$ (Tappert et al., 2013), which in turn is also similar to the average modern C3 plant value (e.g., Kohn, 2010).

The significant difference between modern resins and amber (Student's $t$-test $-t(59)=$ 7.94; $\mathrm{p}<0.001)$ most possibly indicates loss of components with low $\delta^{13} \mathrm{C}$ value at an early stage of maturation. This is in accordance with our FTIR results (Fig. 10b), where the vibrational peak of the carbonyl and some ester groups are lower compared to modern resins (see at 1700 and $1243 \mathrm{~cm}-1$ Figs 8 and 10b) indicating breakdown of acetate consisting compounds during maturation. In our fossil dataset a temporal decrease in the average isotopic values can be observed from the late middle Miocene to the latest Miocene, with a drop of $1.2 \%$ followed by a sudden increase of $3 \%$ in the Pliocene (see Table 3 and Fig. 10c). This could be explained by changes in some of the above-mentioned environmental factors. Dipterocarps are typical tropical trees, most common at lower altitudes (<800m, Asthon, 2004). The declining isotope trend during the Miocene (Fig. 10c) for example can suggest increasing mean annual precipitation and/or enhanced canopy effect with time (Kohn, 2010) in our Bornean low latitude rainforests. The global large-scale carbon isotope database on various amber types also shows a similar trend during the Miocene (Tappert et al., 2013). However, the declining trend on Borneo is also associated with enhanced standard deviation towards the younger samples that allows alternative interpretations such as: (1) ambers originated from wider regions with different environmental background; (2) re-worked specimens within the younger deposits; or (3) increased amount of less mature samples within the younger deposits (see FTIR and GC data in Figs 7-9).

On the other hand, the youngest amber samples from the Pliocene Berakas outcrop yielded the highest dipterocarp isotopic values for the entire dipterocarp dataset $(-25.4 \pm$ $0.2 \%, n=3)$. These exceptionally high Pliocene $\delta^{13} \mathrm{C}$ values may reflect origin and transport from a much higher altitude (e.g., Dal Corso et al., 2017) of the hinterland area of Brunei 
(i.e., Crocker Range). However, a more plausible interpretation is that they rather indicate some enhanced local effects that could have been triggered by some global changes. The higher values could reflect a somewhat cooler-drier condition in the ever-wet, warm tropical forest ecosystems, which is in accordance with palynology data. During the late Pliocene, increased seasonality is detected in the pollen record of Southeast Asia that was likely the consequence of the onset of the northern hemisphere glaciation and related cooling (Morley, 2012). However, a more detailed study with more samples and also better age constraints is necessary for this site to further support this interpretation.

\subsection{The fate of the "Borneo ambers"}

Generally, amber and resinite are commonly found in coal and lignite deposits sometimes buried together with the remains of the producing tree. However, amber is often transported from the original depositional site of soil or swamp and can be accumulated elsewhere such as in riverbanks, river mouths (i.e., delta or estuary), or in shallow-marine, coastal environments. These can be individual pieces with different degree of corrosion, but amber can be enclosed in drift wood as well. Moreover, already embedded material can be reworked/redeposited when older sedimentary rocks are exposed to weathering. All these stages are clearly visible in Brunei. In the hinterland, the dominant mixed dipterocarp forests grow together with some Agathis, producing modern resin, whereas the exposed Neogene rocks locally contain lots of amber. Meanwhile, tree resin and/or amber are washed up from time to time on the beach by the waves and carried to a new depositional site. Such a cycle is continuous and repetitive in northern Borneo since at least the Neogene (Fig. 11).

Most of the recovered Brunei ambers show the effect of transport from their original forest source, and some may have been reworked a few times before being deposited into their final burial site. As the modern rainforest with its dominant dipterocarps is continuously producing resin, ambers and resin with completely different original sources can be mixed, especially in beach deposits. The direct origin of washed-up samples is hard to assess because most of the rock formations that yielded ambers are cut through by rivers, or adjacent to the coastline and their fossil content is easily weathered out, transported, and deposited in younger settings. Nevertheless, the few more recently reworked samples collected from the beach (PB, Mua) or from Pleistocene white sand (SP) show somewhat more enhanced maturity than modern resin collected in the forests based on their FTIR 
results. Other samples, on the other hand, were found in soil (see Tasek Lama, Figs 2 and 3f). At first it was not clear whether these are remnants from the weathered underlying Miocene rocks of the Belait Fm., or if they are from much younger rather modern/submodern tree remains that died and became part of the soil. C-14 dating of these samples revealed much younger ages (500-2500 years) than the sediments underneath, hence they are still considered as resin. As it was expected, the fresh part of these somewhat older resins yielded FTIR spectra and carbon isotopic compositions comparable to the ones of modern tree resins of Borneo (Figs 8 and 10; Table 3).

\section{Conclusion}

Modern tree resins and ambers from Borneo, with a focus on Brunei specimens covering a time range from $12 \mathrm{Ma}$ till today were investigated. All ambers yielded similar FTIR spectra that are comparable with modern dipterocarp tree resins. There has been no indication of Agathis (Araucariaceae) in the fossil record so far, which is another common resin producer of the region. This absence could be explained by the lower abundance of this tree in Borneo's forests compared to the dipterocarps.

We found that some details in the FTIR spectra can help separating modern and fossil dipterocarp resins, which are linked to different stages of maturation. This is further supported by GC analyses, significant differences in average $\delta^{13} \mathrm{C}$ values, and also by basic physical tests. The small negative shift in $\delta^{13} \mathrm{C}$ from the late middle Miocene to the latest Miocene can be interpreted as increased MAP and/or canopy effect in the region, or by an increased amount of less mature specimens among the younger Miocene samples. On the contrary, the highest obtained $\delta^{13} \mathrm{C}$ values from the Pliocene samples are interpreted here as a result of the cooler-drier periods related to increased seasonality that was triggered by the onset of the northern hemisphere glaciations.

Some ambers yielded insect inclusions and also leaf imprints likely of dipterocarp origin. These entrapments happened when the resin was still soft. Already hardened resin/ambers were affected by the boring bivalve Martesia, (i.e., many ambers bear holes), and also by oyster and bryozoan encrustations were observed, suggesting that the ambers were transported from the resin-producing trees into the ocean. The physical appearances of the collected ambers clearly indicate abrasion during transport, and reworking and timeaveraging of different generations seems not uncommon. This process is still observed today 
as tree resin and/or ambers are kept washing up on the beach by the waves and carried to new depositional sites. Such a cycle is continuous and repetitive since at least the Neogene in northern Borneo.

Outlooks for future studies include:

(1) Trace element composition of ambers, which may help clarifying taphonomical processes, identifying mixed assemblages and their subsequent original provenances.

(2) More detailed study on the late Pliocene with better age constraints necessary to further prove a link to global glaciation.

(3) The amber inclusions with their insect fauna can provide further knowledge on paleobiodiversity in Borneo during the last 12 Myrs.

(4) Wider comparative FTIR, GC and NMR studies of several different modern dipterocarp species to further characterize this type of resin. Such analyses might reveal some lower taxonomic variation. Additionally, spectra from the members of the tree genus Mastixia (Nyssaceae) need to be included for comparison.

\section{Acknowledgment}

We are very grateful to Jonathan Hobley, Barbara Kosmowska-Ceranowicz and Siti Nur Faezah H. Ajak for their contribution to FTIR spectroscopy or GC analyses, and to Han Raven for pointing out the taxonomical group of the boring bivalves. L.K. and A.B. received supports from two university research grants of the Universiti Brunei Darussalam: UBD/PNC2/2/RG/1(325) and 1(326) from which most of the fieldwork for collecting the ambers was covered. The research was also supported by the European Union and the State of Hungary, co-financed by the European Regional Development Fund in the project of GINOP-2.3.2.-15-2016-00009 'ICER'. The critical and constructive comments and suggestions of two anonymous reviewers, and the efficient editorial handling of André Strasser are greatly appreciated.

\section{References}

Anderson, K.B., 1996. The nature and fate of natural resins in the geosphere- VII. A radiocarbon age scale (14C) for description of immature resins: an invitation to scientific debate. Geochemistry 25, 251-253. 
Anderson, K.B., Muntean, J.V., 2000. The nature and fate of natural resins in the geosphere. Part X. Structural characteristics of the macromolecular constituents of modern Dammar resin and Class II ambers. Geochem. T. 1, http://dx.doi.org/10.1186/14674866-1-1.

Anderson, K.B., Winans, R.E., Botto, R.E., 1992. The nature and fate of natural resins in the Geosphere. II. Org. Geochem. 18, 829-841.

de Andrade, M.L., Cesare, B.C., 2004. First record of ants from Borneo amber (Hymenoptera, Formicidae). Mitt. Schweiz. entomol. Ges. 11, 247-250.

Ansel, A.D., Nair, N.B., 1969. The mechanisms of boring in Martesia striata Linne (Bivalvia: Pholadidae) and Xylophaga dorsalis Turton (Bivalvia: Xylophaginidae). Proc. R. Soc. Lond. B 174, 123-133.

Ashton, P.S., 2004. Dipterocarpaceae, in: Soepadmo, E., Saw, L.G., Chung, R.C.K. (Eds). Tree flora of Sabah and Sarawak, vol. 5. Sabah Forestry Department, Forest Research Institute Malaysia and Sarawak Forestry Department, Malaysia, pp. 65-388.

Back, S., Tioe, H.J., Thang, T.X., MORLEY, C.K. 2005. Stratigraphic development of synkinematic deposits in a large growth-fault system, onshore Brunei Darussalam. Journal of the Geological Society, London, 162, 243-257.

Bickel, D.J., 2009. The first species described from Cape York amber, Australia: Chaetogonopteron bethnorrisae n.sp. (Diptera: Dolichopodidae). Denisia 26, zugleich Kataloge der oberösterreichischen Landesmuseen Neue Serie 86, 35-39

Böhme, M., Aiglstorfer, M., Antoine, P.-O., Appel, E., Havlik, P., Métais, G., Laq The Phuc, Schneider, S., Setzer, F., Tappert, R., Dang Ngoc Tran, Uhl, D., Prieto, J., 2013. Na Duong (northern Vietnam) - an exceptional window into Eocene ecosystems from Southeast Asia. Zitteliana A 53, 121-168.

Brackman, W., Spaargaren, K., Van Dongen, J.P., Couperus, P.A., Bakker, F., 1984. Origin and structure of the fossil resin from an Indonesian Miocene coal. Geochim. Cosmochim. Acta 48, 2483-3487.

Brody, R.H., Edwards, H.G., Pollard, A.M., 2001. A study of amber and copal samples using FT-Raman spectroscopy. Spectrochim. Acta A 57, 1235-1338.

Colchesterd, M., Webb, G., Emseis, P., 2006. Amber-like fossil resin from north Queensland. Australian Gemmol. 22, 378-385. 
Collins, D.S., Johnson, H.D, Allison, P.A., Guilpain, P., Damit, A.R., 2017. Coupled 'stormflood' depositional model: Application to the Miocene-Modern Baram Delta Province, north-west Borneo. Sedimentology 64, 1203-1235.

Coward, J.A., Mays, C., Patti, F.A., Stilwell D.J., O’Dell, A.L., Viegas, P., 2018. Taphonomy and chemotaxonomy of Eocene amber from southeastern Australia. Org. Geochem. 118, 103-115.

Csongor, É., Szabó, I., Hertelendi, E. , 1983. Preparation of counting gas of proportional counters for radiocarbon dating. Radiochemical and Radioanalytical Letters 55, 303310.

Dal Corso, J., Schmidt, A.R., Seyfullah, L.J., Preto, N., Ragazzi, E., Jenkyns, H.C., Delclòs, X., Néraudeau, D., Roghi, G., 2017. Evaluating the use of amber in palaeoatmospheric reconstructions: The carbon-isotope variability of modern and Cretaceous conifer resins. Geochim. Cosmochim. Acta 199, 351-369.

Dutta, S., Mallick, M., Bertram, N., Greenwood, P.F., Matthews, R.P., 2009. Terpenoid composition and class of Tertiary resins from India. Int. J. Coal. Geol. 80, 44-55.

Dutta, S., Tripathi, S.M., Mallick, M., Matthews, R.P., Greenwood, P.F., Rao, M.R., Summons, R.E., 2011. Eocene out-of-India dispersal of Asian dipterocarps. Rev. Palaeobot. Palyno. $166,63-68$.

Farjon, A., Filer, D., 2013. An Atlas of the World's Conifers. Brill, Leiden.

Grimaldi, D.A. Engel, M.S., Nascimbene, P.C. 2002. Fossiliferous Cretaceous Amber from Myanmar (Burma): Its Rediscovery, Biotic Diversity, and Paleontological Significance. Am. Mus. Novit. 3361, 1-71.

Harzhauser, M., Raven, H., Landau, B., Kocsis, L., Adnan, A., Zuschin, M., Mandic, O., Briguglio, A., 2018. Late Miocene gastropods from northern Borneo (Brunei Darussalam, Seria Formation). Palaeontographica, abt. A: Palaeozoology-Stratigraphy $313,1-79$.

Havelcová, M., Sýkorová, I., Mach, K., Dvořák, Z., 2014. Organic geochemistry of fossil resins from the Czech Republic. Procedia Earth and Planetary Science 10, 303-312.

Hillmer, G., Weitschat,W., Vávra N., 1992. Bernstein aus dem Miozän von Borneo. Nat.wiss. Rundsch. 45, 72-74.

Hertelendi, E., Csongor, É., Záborszky, L., Molnár, J., Dajkó, G., Györffi, M., Nagy, S., 1989. A counter system for high-precision 14C dating. Radiocarbon 31, 399-406. 
Hutchison, C.S., 2005. Geology of North West Borneo: Sarawak, Brunei and Sabah. Elsevier, Amsterdam.

Kessler, F.L., Jong, J., 2015. Tertiary Uplift and the Miocene Evolution of the NW Borneo Shelf Margin. Berita Sedimentologi 44, 21-57.

Kocsis, L., Briguglio, A., Roslim, A., Razak, H., Corić, S., Frijia, G., 2018a. Stratigraphy and age estimate of Neogene shallow marine fossiliferous deposits in Brunei Darussalam (Ambug Hill, Tutong district). J. Asian Earth Sci. 158, 200-209.

Kocsis, L., Razak, H., Briguglio, A., Szabó, M., 2018b. First report on a diverse Neogene fossil cartilaginous fish fauna from Borneo (Ambug Hill, Brunei Darussalam). Journal of Systematic Palaeontology, https://doi.org/10.1080/14772019.2018.1468830.

Kohn, M.J., 2010. Carbon isotope compositions of terrestrial C3 plants as indicators of (paleo) ecology and (paleo) climate. PNAS 107 (46), 19691-19695.

Kosmowska-Ceranowicz, B., 2015. Infrared spectra atlas of fossil resins, subfossil resins and selected imitations of amber. in: Kosmowska-Ceranowicz, B., Vávra, N. (Eds.) ATLAS, Infrared Spectra of the World's Resins. Holotype Characteristics. Polska Akademia Nauk Muzeum Ziemi w Warszawie, pp. 5-213.

Kosmoswska-Ceranowicz,B., Sachanbiński, M., Łydżba-Kopczyńska,B., 2017. Analytical characterization of "Indonesian amber" deposits: Evidence of formation from volcanic activity. Baltica 30/1, 55-60.

Lambert, J.B., Levy, J.A., Santiago-Blay, A.J., Wu, Y.Y., 2013. Nuclear Magnetic Resonance Characterization of Indonesian Amber. Life: The Excitement of Biology 1(3), 136-155. Lambiase, J.J., Cullen, A.B., 2013. Sediment supply systems of the Champian "Delta" of NW Borneo: Implications for deepwater reservoir sandstones. J. Asian Earth Sci. 76, 356371.

Langenheim, J.H., Beck, W.C., 1965. Infrared spectra as a means of determining botanical source of amber. Science 149, 52-55.

Langenheim, J., 2003. Plant Resins. Chemistry, Evolution, Ecology, and Ethnobotany. Timber Press, Portland.

de Laubenfels, D.J. 1988. Coniferales. in Flora Malesiana, Series I, Vol. 10. Dordrecht: Kluwer Academic, pp. 337-453.

Liechti, P., Roe, F.N., Haile, N.S., Kirk, H.J.C., 1960. The Geology of Sarawak, Brunei and the Western Part of North Borneo. Bulletin 3, Volumes 1\&2. Geological Survey 
Department British Territories in Borneo. Government Printing Office, Kuching, Sarawak.

Lyons, P.C., Masterlerz, M., Orem, W.H., 2009. Organic geochemistry of resins from modern Agathis australis and Eocene resins from New Zealand: diagenetic and taxonomic implications. Int. J. Coal. Geol. 80, 51-62.

Muller, J., 1981. Fossil pollen records of extant angiosperms. The Botanical Review 47/1, 1140.

Morley, R.J., 2000. Origin and evolution of tropical rain forests. Chichester: John Wiley and Sons.

Morley, R.J., 2012. A review of the Cenozoic palaeoclimate history of Southeast Asia, in: Gower, D. et al. (Eds). Biotic Evolution and Environmental Change in SE Asia, Systematics Association, Cambridge University Press pp. 79-114.

Murray, A.P., Edwards, D., Hope, J.M., Boreham, C.J., Booth, W.E., Alexander, R.A., Summons R.E., 1998. Carbon isotope biogeochemistry of plant resins and derived hydrocarbons. Org. Geochem. 29, 1199-1214.

Murray, A.P., Summons, R.E., Boreham, C.J., Dowling, L.M., 1994a. Biomarker and n-alkane isotope profiles for Tertiary oils: relationship to source rock depositional setting. Org. Geochem. 22, 521-542.

Murray, A.P., Padley, D., McKirdy, D.M., Booth, W.E., Summons, R. E., 1994b. Oceanic transport of fossil dammar resin: the chemistry of coastal resinites from South Australia. Geochim. Cosmochim. Acta 58, 3049-3059.

Nordt, L., Tubbs, J., Dworkin, S., 2016. Stable carbon isotope record of terrestrial organic materials for the lest 450 Ma yr. Earth Sci. Rev. 159, 103-117.

Poinar Jr., G.O., 1991. Resinites, with examples from New Zealand and Australia. Fuel processing Technology 28, 135-148.,

Poinar Jr., G.O., 1992. Life in Amber. Stanford University Press, Stanford.

Poinar Jr., G.O., Mastalerz, M., 2000. Taphonomy of fossilized resins: determining the biostratinomy of amber. Acta Geologica Hispanica 35, 171-182.

Poinar, G., Lambert, J.B., Wu, Y., 2007. Araucarian source of fossiliferous Burmese amber: Spectroscopic and anatomical evidence J. Bot. Res. Inst. Texas 1(1): $449-455$. Pourchon, R.D., 1956. A note on the biology of Martesia striata L. (Lamellibranchia). Proc. Zool. Soc. London. 126, 245-258. 
Reimer, P.J., Bard, E., Bayliss, A., Beck, J.W., Blackwell, P.G., Bronk Ramsey C., Buck, C.E., Cheng, H., Edwards, R.L., Friedrich, M., Grootes, P.M., Guilderson, T.P., Haflidason, H., Hajdas, I., Hatté, C., Heaton, T.J., Hogg, A.G., Hughen, K.A., Kaiser, K.F., Kromer, B., Manning, S.W., Niu, M., Reimer, R.W., Richards, D.A., Scott, E.M., Southon, J.R., Turney, C.S.M., van der Plicht, J. 2013. IntCal13 and MARINE13 radiocarbon age calibration curves 0-50000 years calBP. Radiocarbon 55(4), 1869-1887.

Roslim, A., Briguglio, A., Kocsis, L., Corić, S., Gebhardt, H., 2019. Large rotaliid foraminifera as biostratigraphic and palaeoenvironmental indicators in northwest Borneo: An example from a late Miocene section in Brunei Darussalam. J. Asian Earth Sci. 170, 20-28.

Ross, A. 2010. Amber: The Natural Time Capsule. New York: Firefly Books.

Ross, A.J., Mellish, C., York, P., Crighton, B., 2010. Chapter 12. Burmese amber, in: Penney, D. (Ed.). Biodiversity of fossils in amber from the major world deposits. Siri Scientific Press, Manchester, pp. 208-235.

Rust, J., Singh, H., Rana, R.S., McCann, T., Singh, L., Anderson, K., Sarkar, N., Nascimbene, P.C., Stebner, F., Thomas, J.C., Solórzano Kraemera, M., Williams, C.J., Engel, M.S., Sahni, A., Grimaldi, D., 2010. Biogeographic and evolutionary implications of a diverse paleobiota in amber from the early Eocene of India. PNAS 107 (43) 18360-18365.

Sandal, S.T., 1996. The Geology and Hydrocarbon Resources of Negara Brunei Darussalam (1996 revision). Brunei Shell Petroleum Co. and Muzium Negara, Syabas Bandar Seri Begawan, Brunei Darussalam.

Schlee, D., Chan, P.H., Dorani, J., Voong, F.K., 1992. Riesenbernsteine in Sarawak, NordBorneo. Lapis 17 (9), 13-23.

Seyfullah, J.L., Sadowski, E.-M., Schmidt, A.R., 2015. Species-level determination of closely related araucarian resins using FTIR spectroscopy and its implications for the provenance of New Zealand amber. PeerJ 3:e1067; DOI 10.7717/peerj.1067.

Seyfullah, L.J., Beimforde, C., Dal Corso, J., Perrichot, V., Rikkinen, J., Schmidt, A.R., 2018. Production and preservation of resins - past and present. Biol. Rev. 93(3), 1684-1714. Slik, J.W.F., Poulsen, A.D., Ashton, P.S., Cannon, C.H., Eichhorn, K.A.O., Kartawinata, K., Lanniari, I., Nagamasu, H., Nakagawa, M., van Nieuwstadt, M.G.L., Payne, J., Purwaningsih, Saridan, A., Sidiyasa, K., Verburg, R.W., Webb, C.O., Wilkie, P., 2003. A floristic analysis of the lowland dipterocarp forests of Borneo. J. Biogeogr. 30, 15171531. 
Smith, R.D.A., Ross, A.J., 2018. Amberground pholadid bivalve borings and inclusions in Burmese amber: implications for proximity of resin-producing forests to brackish waters, and the age of the amber. Earth Environ. Sci. Trans. R. Soc. Edinb. Special Issue: Fossil Insects, Arthropods and amber, Vol. 107, 239-247.

Spiker, E.C., Hatcher, P.G., 1987. The effects of early diagenesis on the chemical and stable carbon isotopic composition of wood. Geochim. Cosmochim. Acta 51, 1385-1391.

Sonibare, O.O., Agbaje, O.B., Jacob. D.E., Faithfull, J., Hoffmann, T., Foley, S.F. 2014.

Terpenoid composition and origin of amber from the Cape York Peninsula, Australia. Aust. J. Earth Sci. 61, 979-985.

Stout, S.A. 1995. Resin-derived hydrocarbons in fresh and fossil Dammar resins and Miocene rocks and oils in the Mahakam Delta, Indonesia, in: Anderson, K.B., Crelling, C.J. (Eds). Amber, Resinite, and Fossil Resins. ACS Symposium Series No. 617. American Chemical Society. Washington, District of Columbia, USA. pp. 42-75.

Stuvier, M., Reimer, P.J., 1993. Extended 14C data base and Revised CALIB 3.0 14C Age Calibration Program. Radiocarbon 35, 215-230.

Tappert, R., Wolfe, A.P., McKellar, R.C., Tappert, M.C., Muehlenbachs, K., 2011.

Characterizing modern and fossil gymnosperm exudates using micro-Fourier transform infrared spectroscopy. Int. J. Plant Sci. 172, 120-138.

Tappert, R., McKellar, R.C., Wolfe, A.P., Tappert, M.C., Ortega-Blanco, J., Muehlenbachs, K., 2013. Stable carbon isotopes of C3 plant resins and ambers record changes in atmospheric oxygen since the Triassic. Geochim. Cosmochim. Acta 121, 240-262.

Tate, R.B., 1973. Palaeo-environmental studies in Brunei. Brunei Museum Journal 3, 285305.

Turner, R.D., 1954. The family Pholadidae in the Western Atlantic and the Eastern Pacific. Part I-Pholadinae. Johnsonia 3(33), 1-64.

Unjah, T., Komoo, I, Dana Badan, D., 2003. Amber Merit Pila. Geological Society of Malaysia, Bulletin 46, 247-253.

Van Aarssen, B.G., Cox, H.C., Hoogendoom, P., de Leeuw, J.W., 1990. A cadinene biopolymer in fossil and extant Dammar resins as a source for cadinanes and bicadinanes in crude oils from South-east Asia. Geochim. Cosmochim. Acta 54, 3021-3031.

Van Aarssen, B.G., de Leeuw, J.W., Collinson, M., Boon, J.J., Goth. K., 1994. Occurrence of polycadinene in fossil and recent resins. Geochim. Cosmochim. Acta 58, 223-229. 
Vávra, N., 2009. Amber, fossil resins, and copal - contributions to the terminology of fossil plant resins. Denisia 26, 213-222.

Vávra, N., 2015. Mineral names used for fossil and subfossil resins ('ambers') and similar materials, in: Kosmowska-Ceranowicz, B., Vávra, N. (Eds.) ATLAS, Infrared Spectra of the World's Resins. Holotype Characteristics. Polska Akademia Nauk Muzeum Ziemi w Warszawie, pp. 215-280.

Wannier, M., Lesslar, P., Lee, C., Raven, H., Sorkhabi, R., Abdullah, I., 2011. Geological excursions around Miri, Sarawak, 1910-2010, celebrating the $100^{\text {th }}$ anniversary of the discovery of the Miri oil field. Shell International EP, Miri, Sarawak, Malaysia.

Wilford, C.E., 1961. The Geology and Mineral Resources of Brunei and adjacent parts of Sarawak with descriptions of Seria and Miri oilfields. British Borneo Geological Survey, Memoir 10.

Zheng, D., Chang, S.-C., Perrichot, V., Dutta, S., Rudra, A., Mu, L., Kelly, R.S., Li, S., Zhang, Q., Zhang, Q., Wong, J., Wang, J., Wang, H., Fang, Y., Zhang, H., Wang, B., 2018. A Late Cretaceous amber biota from central Myanmar. Nature Communications, 9 (3170), 16.

\section{Figure Captions}

\section{Figure 1}

(a-b). The studied region and the geographical origin of some of the investigated samples. Green triangles are modern tree resin localities in Brunei and Malaysia (see also Table 1): Sep - Sepliok in Sabah, Malaysia; Bad - Badas; Ter Tereja; AFR - Andulau Forest Reserve; TL - Tasek Lama; Ulu - Ulu ulu National Park are all sites where dipterocarp forests dominate and the resins were obtained directly from living trees (Sep, Ulu), from fallen, dead trees (Ter, Bad), collected from forest floor (AFR) or from soil (TL). Ag - Agathis borneensis is an araucarian that can also produce a large amount of resin and is widely distributed in Southeast Asia. The blue circle marks Miri in Sarawak from where Miocene fossil tree resins were obtained. (c). Three tree families that produce plant exudates. Dipterocarps are the most dominant trees in the tropical rainforest of Southeast Asia. They together with araucarians produce terpenoid-based resin, while fruit trees rather yield water-soluble polysaccharides, called gum. Hence the presence of the latter in the fossil record is 
unexpected. The three groups can be easily distinguished by their FTIR spectra (see also Fig. 7). The red arrows indicate where the resin samples were taken.

\section{Figure 2}

(a). Geological origin and (b) age distributions of the studied fossil tree resins collected in Brunei (see also Fig. 1). The simplified geological map and the age range of the lithostratigraphic units are based on Sandal (1996). For the abbreviations and more details on the sites see Table 1.

\section{Figure 3}

(a-e) Fossil and (f) modern tree resins in the field. (a). Fossil resin with woody external part Ambug Hill (AH), base of unit 2, shallow coastal-marine deposit - Seria Fm.; (b) Big rounded amber - Subok (Sub1) from red cast bed - Belait Fm.; (c) small woody amber pieces - Berakas Beach (Ber2) - fluvial, organic-rich deposits; (d) drift wood with amber (AH4/1) - Ambug Hill, top part of the clay near R4 bed (see Kocsis et al., 2018a). The white arrows show the amber specimens in the layers. (e) Small transparent amber piece showing flow structure. $-J$ In. Pak Bidang (JPB1) - Seria Fm. (f) Tree resins cropping out of the soil in Tasek Lama. C-14 dating indicates an age range of 500 to 2500 years for these resins.

\section{Figure 4}

Common types of fossil tree resin specimens from Brunei. (a) Big, rounded specimen indicating long transport and abrasion - $\mathrm{AH}$. (b) Large amber with woody external part and opaque orange and greenish internal part - AH. (c) Several small amber specimens from JPB1. Note the most common orange and reddish color. (d) Opaque, orange amber from AH. Note the rounded holes that derived from boring bivalves (see Fig. 5). (e) A specimen covered fully with holes as a result of bioerosion by boring bivalves - JBB1. (f) Streamlined amber with woody structures at the external surface, found washed-up on the beach (PB). (g) Black coloured amber (AH-3). (h) Fossil drift wood with voids filled by amber. Some are indicated by arrows $-\mathrm{AH}$.

\section{Figure 5}


Bioerosion and inclusions in the ambers. (a) Elongated, streamlined amber with Martesia bivalve domichnia, a permanent dwelling structure. The arrows mark the hole on the surface where the organism connected to the external environment - $\mathrm{AH}$, unit 2. (b) Cast and mold of Martesia boring bivalve in amber from $\mathrm{AH}$. The arrow indicates the hole where the top right close-up on the imprint was taken. Bottom left is a cast fallen out from the same amber specimen - AH, unit 2. (c) Oyster grown on amber pieces in two different views - PT. (d) Bryozoan encrustation on an amber pebble from Miri. (e) Leaf imprint in an opaque amber$\mathrm{AH}$, unit 3. (f-h) Insects trapped in ambers found in the Subok area (Sub2 and 3).

\section{Figure 6}

Illustration of the results of some of the physical tests carried out on selected amber and modern resin specimens. (a) Sub1 - Subok, Belait Formation late middle Miocene. (b) JT1-1 - Tanjong Nangka site, Miri Fm., late Miocene. (c) Amb2 - Ambug Hill, unit 2, Seria Fm., late Miocene. (d) Ber1 - Berakas Beach outcrop - Liang Fm., Pliocene. (e) TL1 - Tasek Lama modern tree resin. (f) Baltic amber collected in Lithuania, Eocene.

\section{Figure 7}

Fourier Transform Infrared (FTIR) analyses and related statistics of the samples (a) FTIR spectra of selected modern and fossil tree resins from Borneo. Note that all the modern and fossil Borneo specimens (62), except the Agathis borneensis, show very similar spectra (blue and green spectra) that can be linked to a dipterocarp origin. The major difference between Agathis borneensis and the dipterocarps can be observed in the spectral region of $1400-$ $1000 \mathrm{~cm}^{-1}$ (grey rectangle): (1) There is an absorption triplet between 1390 and $1360 \mathrm{~cm}^{-1}$ with a maximum at $1384 \mathrm{~cm}^{-1}$ (see close-up on the top right) and (2) the relatively lower absorption peaks in the $1100-1300 \mathrm{~cm}^{-1}$ range when compared to the Agathis resins. Additionally, the largest peak for Agathis is in the double bonds absorptions region $\sim 1700 \mathrm{~cm}^{-1}$, while for the dipterocarps is at the single $\mathrm{C}-\mathrm{H}$ of $2956 \mathrm{~cm}^{-1}$. (b) Principal Component Analyses (PCA) of 60 dipterocarp-like resin based on their 18 FTIR peaks (see Table 2). The colour code of the samples follows the lithostratigraphic units displayed in Figure 2. Note the clear separation of modern resin (grey field), though with a few fossil specimens that overlap. Samples with bold and coloured marks are those that run for GC-MS measurement (modern: AFR-1a, Bad, TL1-2int; fossils: Ber-3, Amb-2, H84-2, JT1-3, Sub1-1). 


\section{Figure 8}

Selected band ratios from the FTIR spectra and their cross-plots illustrate some differences between modern and fossil dipterocarps. Close-up of the FTIR spectral region of 1800-1000

$\mathrm{cm}^{-1}$ shows the selected absorption peaks. Note that the exact peak positions slightly vary among the samples (see chapter 4.3 and Table 2), however, the exact peak maxima were always chosen for the calculation of the ratios. The Miocene samples were grouped together for the three formations as they do not show significant differences for these band ratios. Note that the few Pliocene samples plot close to the modern specimens, but ambers found on the beach (i.e., transported, reworked) would plot more closely with the fossil samples. There is still a clear overlap between modern and fossil specimens that may indicate variable maturation stages of the samples. On the plot $1700 / 1460$ vs. $1384 / 1243$ samples run for GCMS are marked together with other samples that overlap with the modern ones (see also Figs 7b and 9). The TL1-2 modern resin has been sub-sampled in its interior (int) and its external (ext), weathered surface. The FTIR spectrum of TL1-2ext (grey) is clearly different with larger background in the spectral region of $1300-1050 \mathrm{~cm}^{-1}$ and with the lack of some fine details as seen on the TL1-2int (or any other dipterocarp spectra).

\section{Figure 9}

Gas-chromatographs derived from methanolic extracts of eight modern and fossil resins from Brunei. The modern samples show a more complex composition with some volatile components that are most remarkable in the AFR-1a sample. Note that most of the fossil samples yielded very similar compounds except $\mathrm{H} 84-2$. This sample is rather grouped with the modern specimens, which probably indicates lower maturity compared to other ambers, even if its geological age (late Miocene) would suggest otherwise. This sample also plots together with the modern resins on FTIR cross plots (see Fig. 8).

\section{Figure 10}

(a) Histogram of carbon isotope composition of fossil and modern dipterocarp tree resins from Borneo. Data are compiled from this study (40), Murray et al. (1994b, 1998) (13) and Stout (1995) (7). Note the more than $3 \%$ o higher mean value for the fossil resins compared to the modern ones. The difference between the means is significant (Student's t-test - 
$t(59)=7.94 ; p<0.001)$. Average data of dipterocarp ambers from the Miocene Merit-Pila mine in Sarawak and from the Eocene of India (Tappert et al., 2013) also fit with the compiled data presented here. (b) Carbon isotopic composition versus $1384 \mathrm{~cm}^{-1} / 1246 \mathrm{~cm}^{-1}$ FTIR band ratio plotted for the Borneo specimens of this study. Note again the distinction between modern and fossil dipterocarp resins. (c) Average variation in carbon isotopic composition of the amber samples through time (see also Table 2).

\section{Figure 11}

Diagram summarising the fate of tree resins and ambers relative to their production, transport, depositional sites, and interaction with the biosphere. Note that similar cycles were proposed for other type of resins and ambers (e.g., Langenheim, 2003; Seyfullah et al 2018).

\section{Table 1}

The investigated localities and the origin of the studied samples with the type of analyses carried out.

\section{Table 2}

Major FTIR absorbance bands and the occurrence of the maxima among the samples separated for modern and fossil specimens. Note that certain absorbance bands have higher variation in their maxima, while others are more consistent. Principal Component Analyses were performed on these peaks ( $n=18$ ) involving 60 different samples (see Fig. $7 b$ ).

\section{Table 3}

Carbon isotopic composition of ambers and modern tree resins. Note that for some specimens duplicates were analysed. In the last column time-averaged isotopic compositions are provided.

\section{Supplementary Material 1}

Figure SM1: Google Earth map of the fossil samples in Brunei Darussalam with the related geographical coordinates. 


\section{Supplementary Material 2}

Table SM2: Preliminary C-14 dates of a few selected samples.

\section{Supplementary Material 3}

Table SM3: Summary of physical tests of twelve selected samples. Nine ambers and two modern tree resins from Brunei and Baltic amber from Lithuania. 


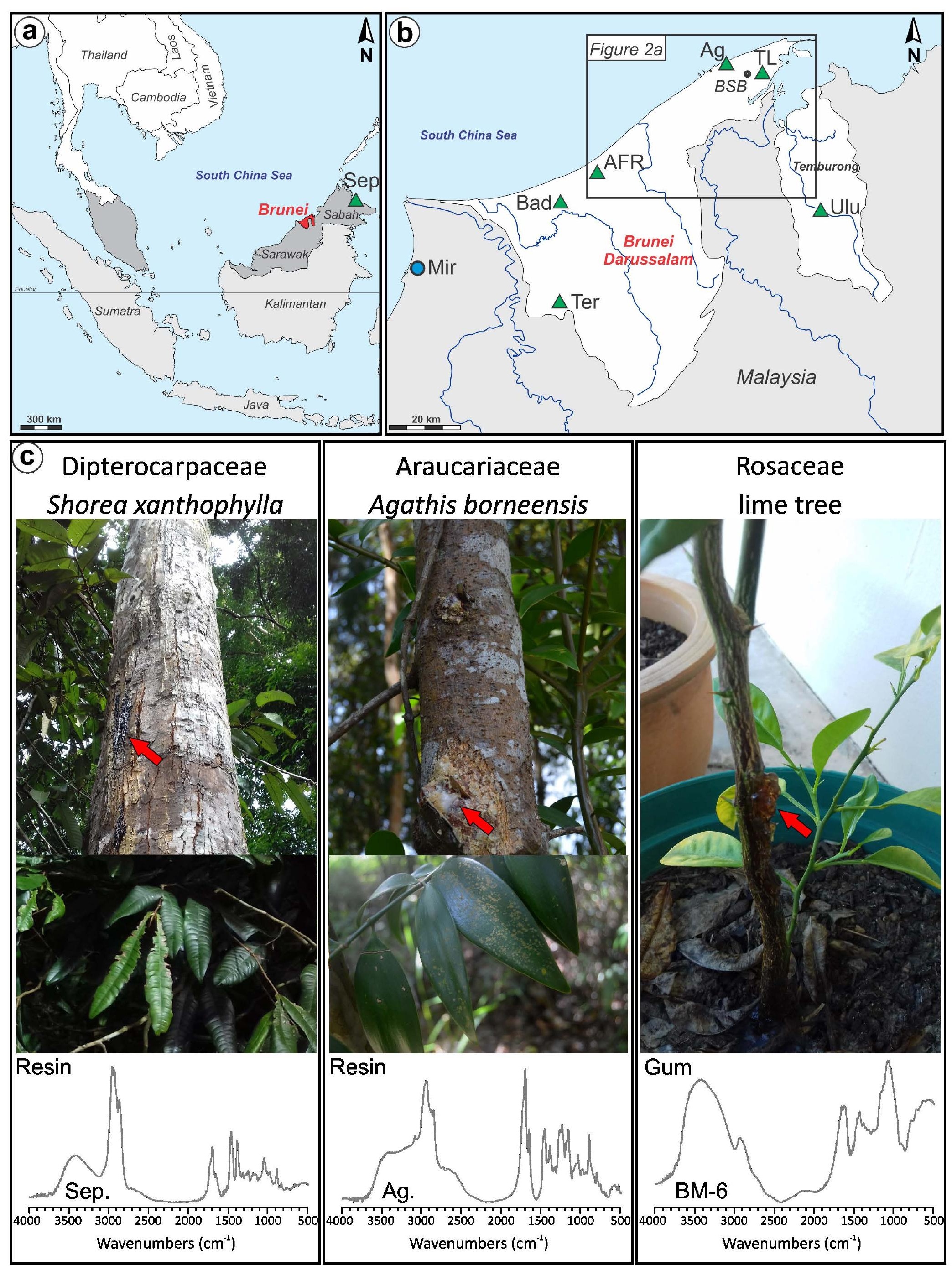



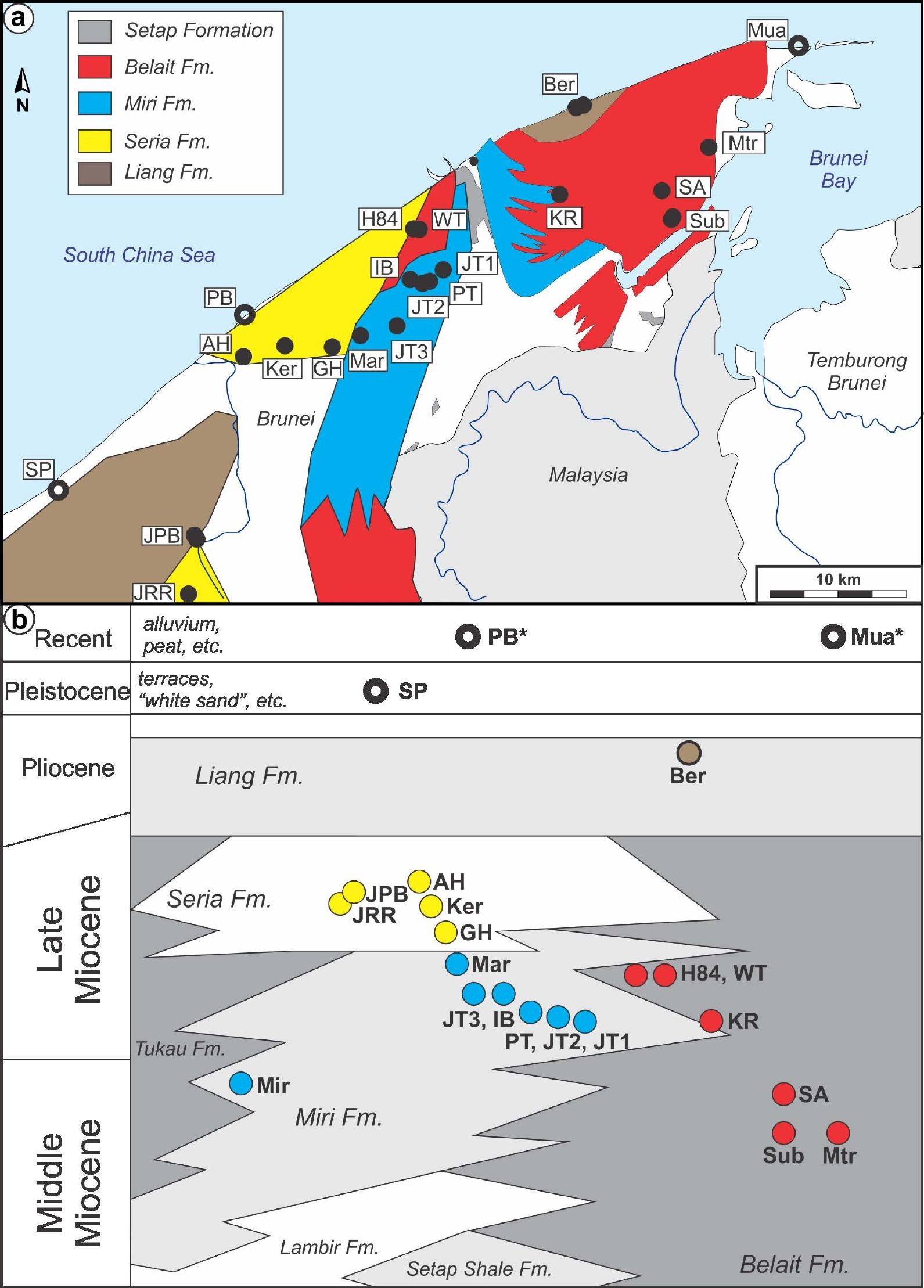

alluvium,
peat, etc.

terraces,

"white sand", etc.

Liang Fm.

Brunei

Bay

Temburong Brunei

Pleistocene "white sand, etc.


(a)

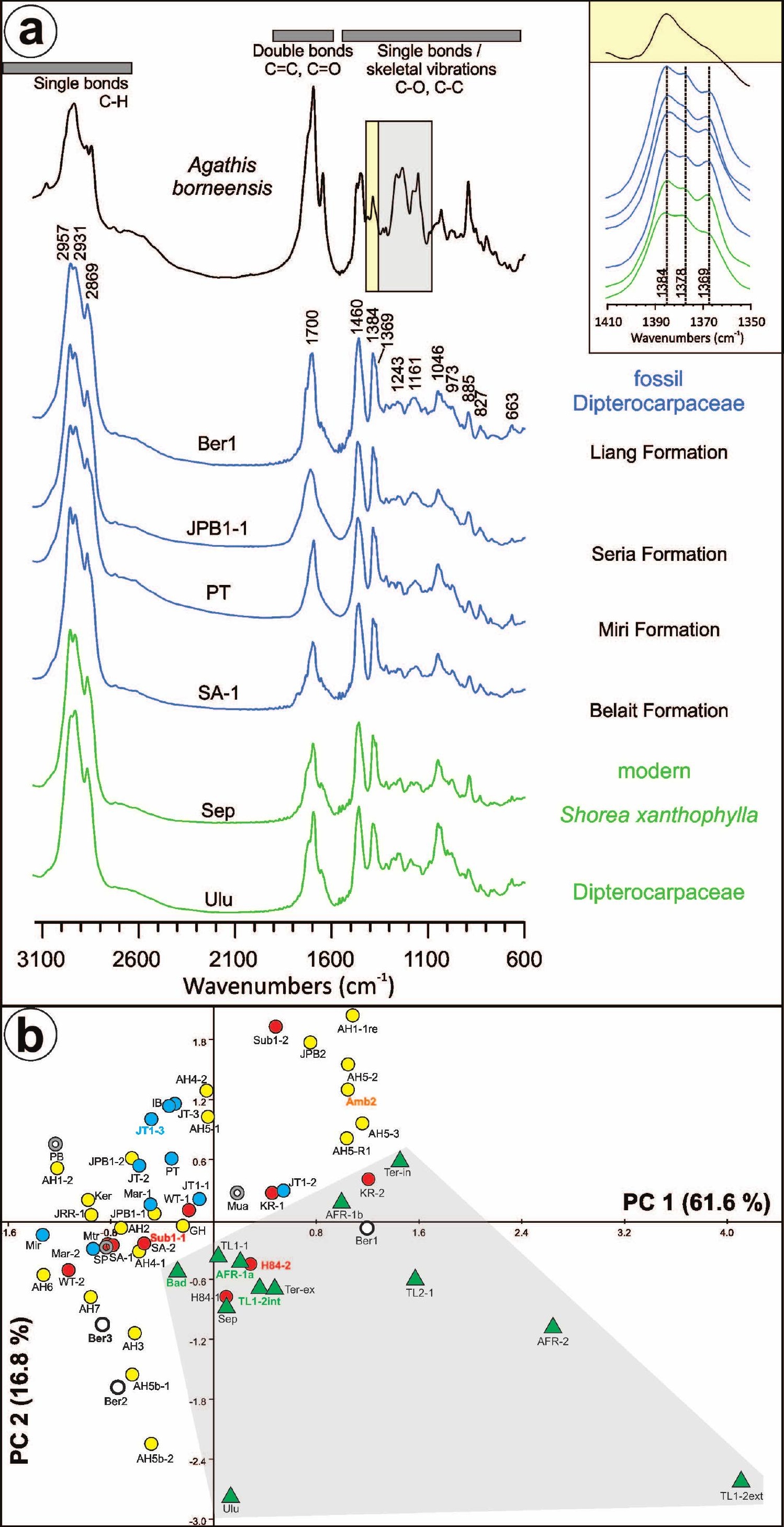

Dipterocarpaceae

Liang Formation

Seria Formation

Miri Formation

Belait Formation

modern

Shorea xanthophylla

Dipterocarpaceae 


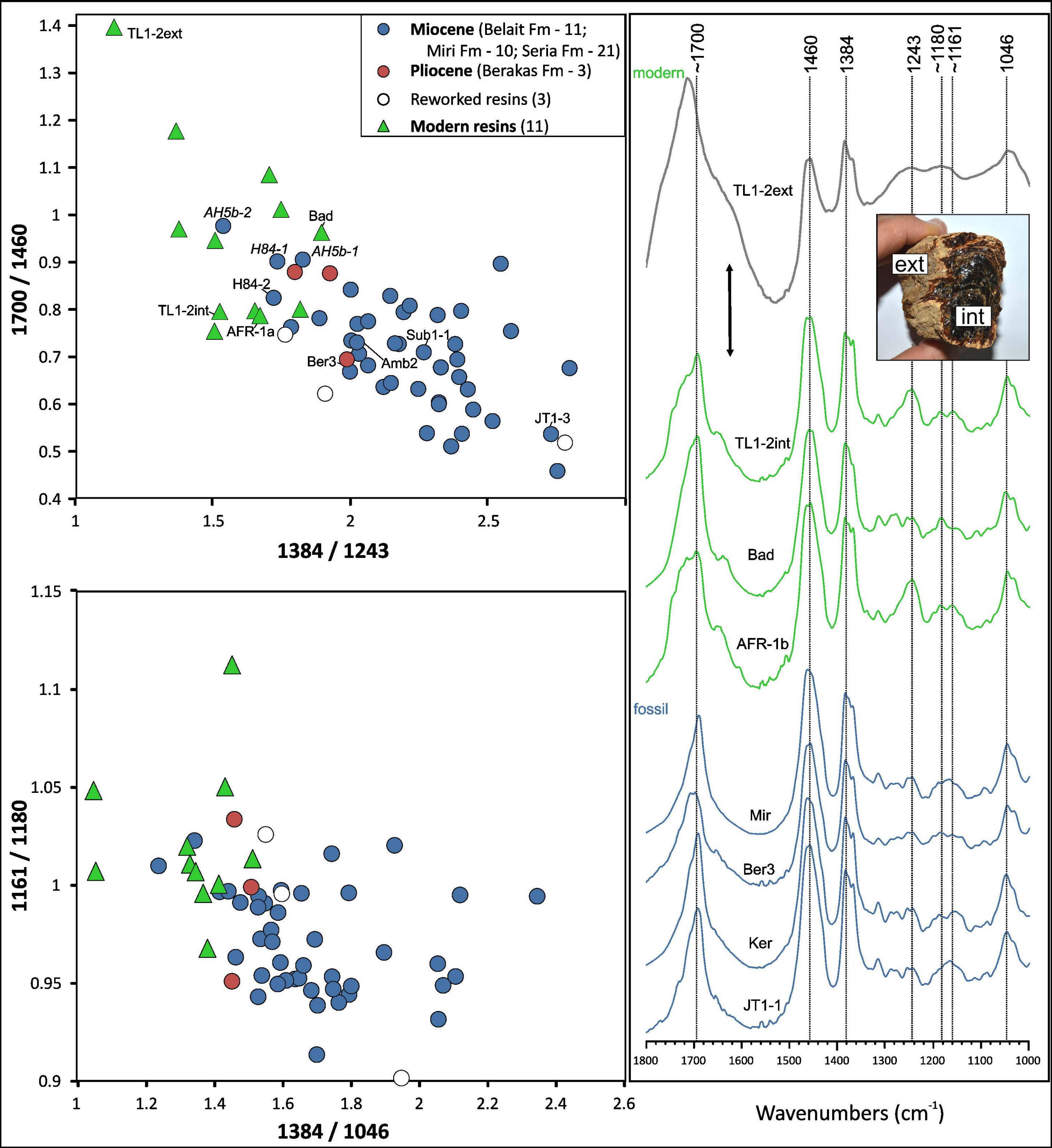




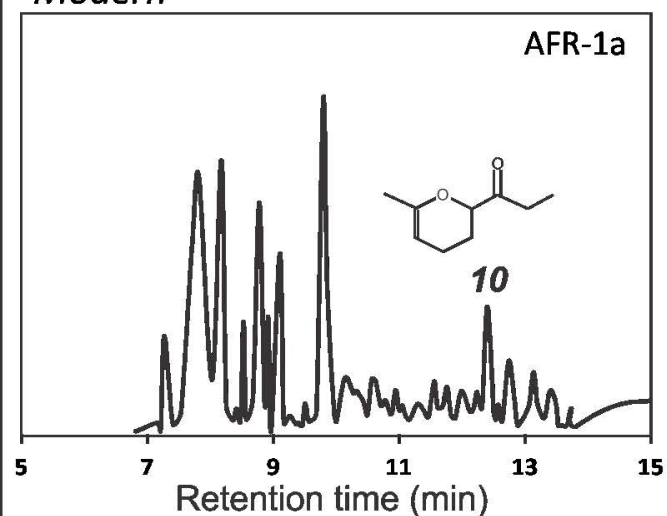

Modern and fossil resins

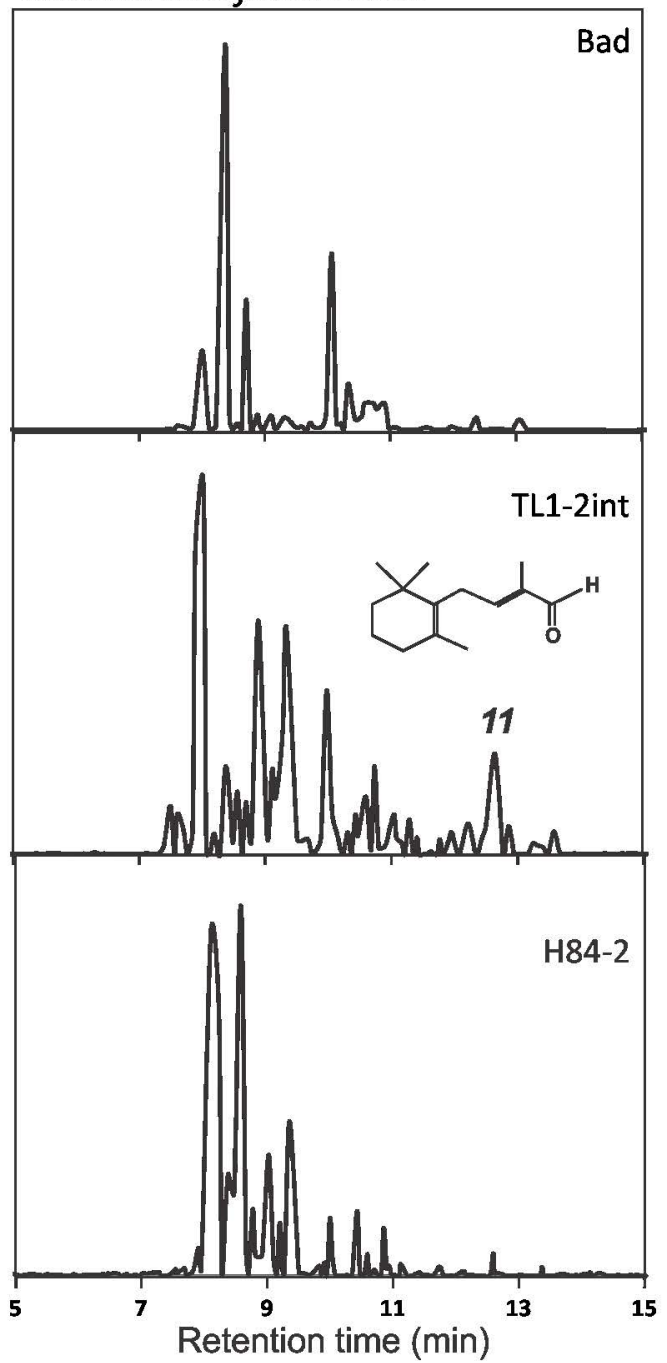

(1) 1,2,4a,5,6,8a-hexahydro-4,7-dimethyl-1-(1-methylethyl)-Naphthalene

(2) Heptane, 2,6-diphenyl-3-methyl-

(3) 1,2,3,4-tetrahydro-1,6-dimethyl-4-(1-methylethyl)-Naphthalene

(4) 3-(2,6,6-trimethyl-1-cyclohexen-1-yl)-2-Propenal

(5) Tetrahydroabietic acid

(6) 1,2,3,4,4a,5,6,8a-octahydro-7-methyl-4-methylene-1-(1-methylethyl)- Naphthalene

(7) Cadina-1(10),6,8-triene

(8) $\alpha$-Cadinol

(9) 3-ethyl-3-hydroxy-(5.alpha.) Androstan-17-one

(10) 2-Propionyl-6-methyl-3,4-dihydropyran

(11) 2-methyl-4-(2,6,6-trimethyl-1-cyclohexen-1-yl)-2-Butenal,
Fossil resins

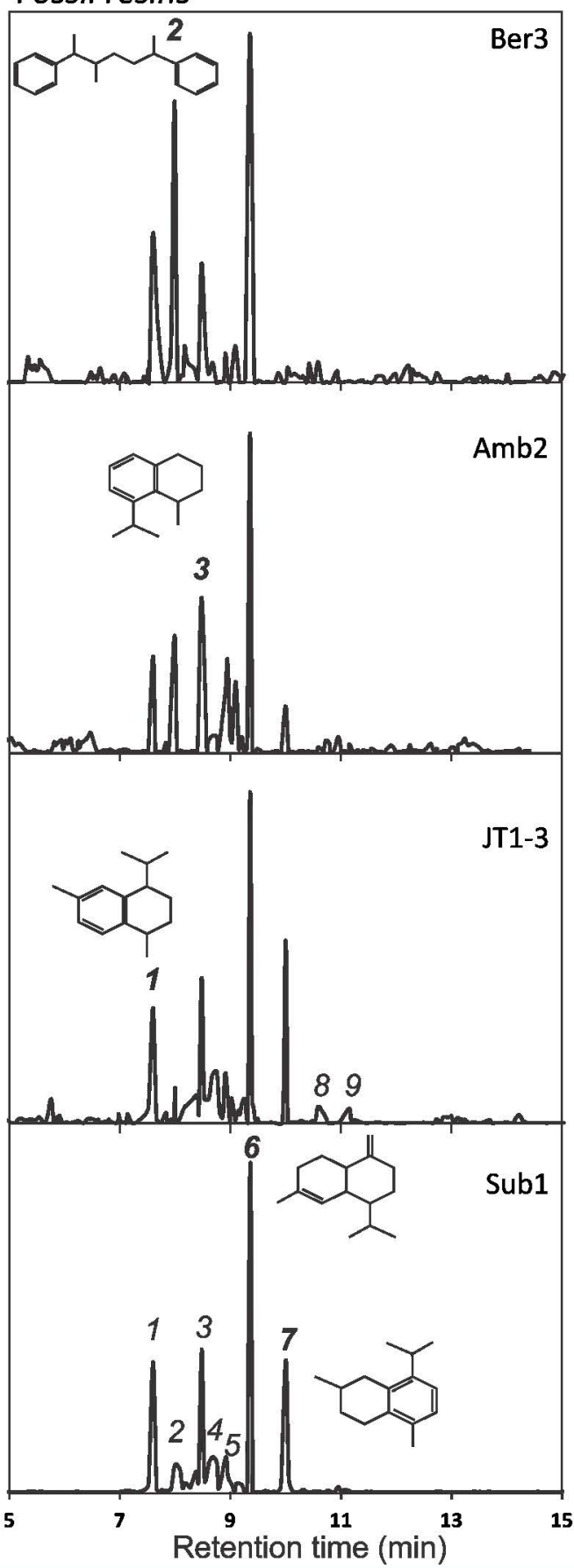




\section{(a)}

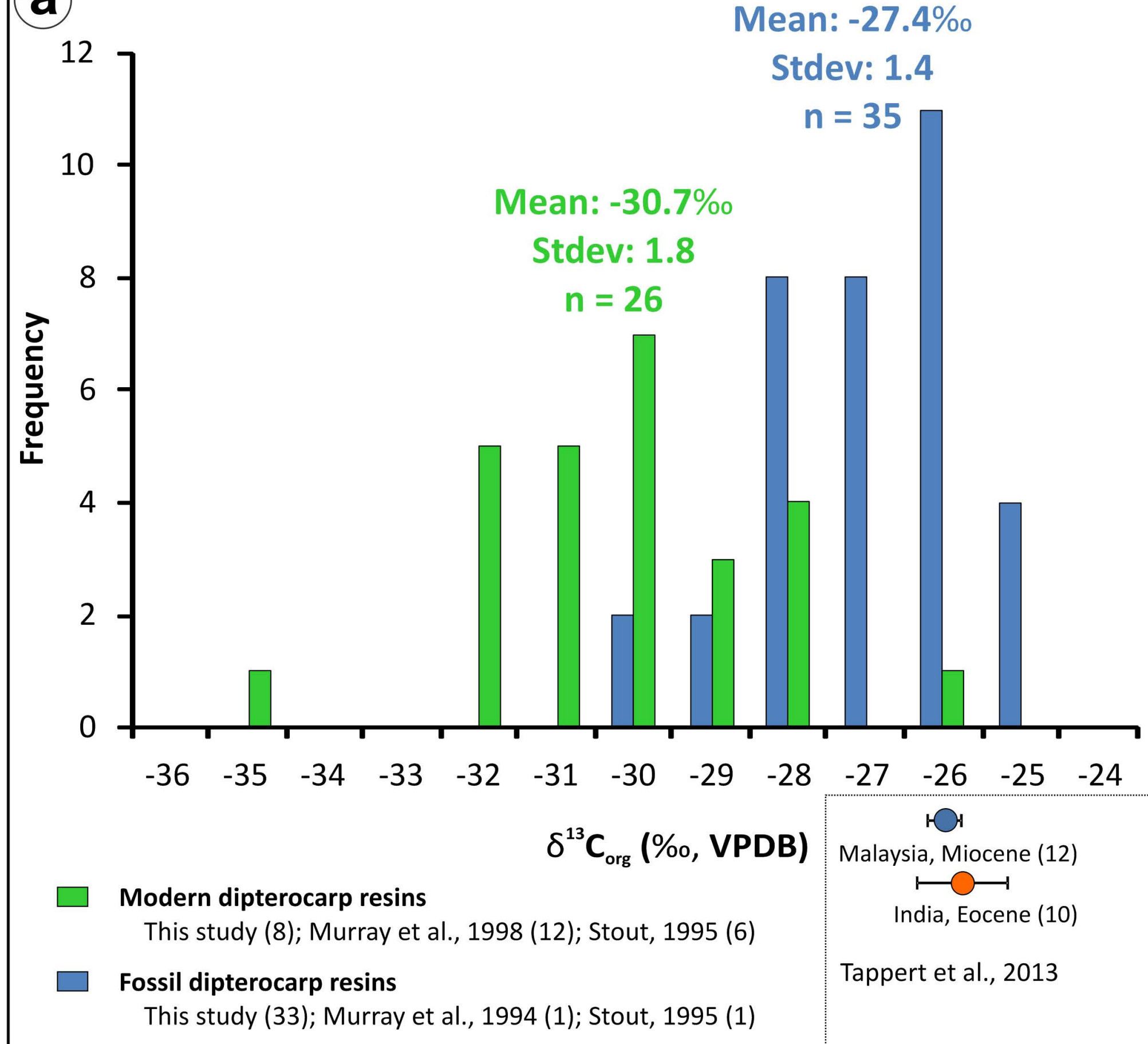

\section{b}

Miocene (Belait Fm - 6;

Miri Fm - 9; Seria Fm - 12)

Pliocene (Berakas Fm - 2)

Reworked resins (3)

$\triangle$ Modern resins (8)

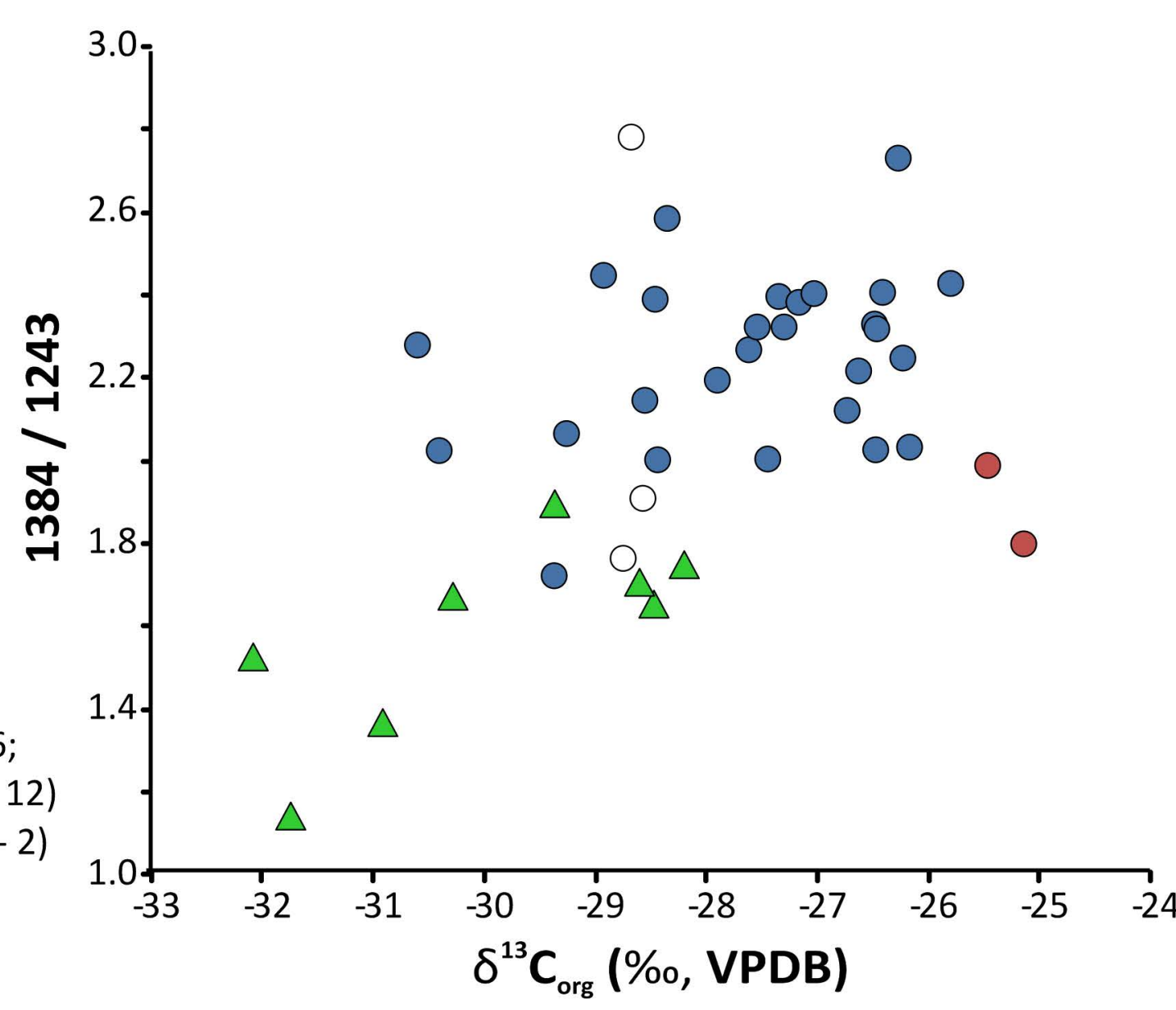

\section{C}

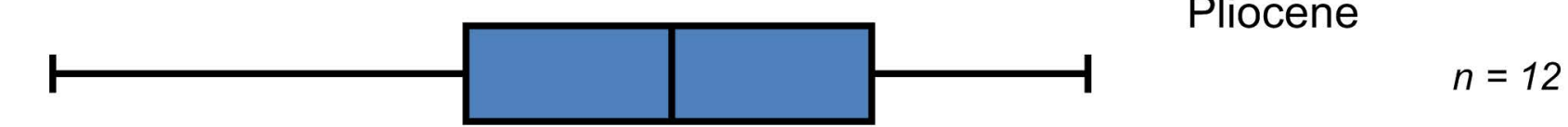

latest Miocene (late Tortonian - Messinian)

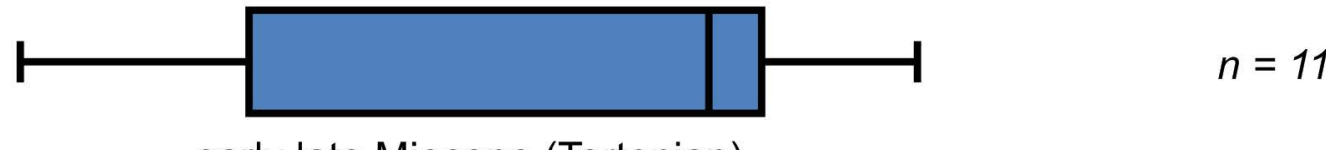

early late Miocene (Tortonian)

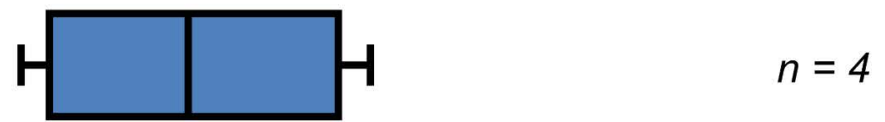

late middle Miocene (Serravallian)

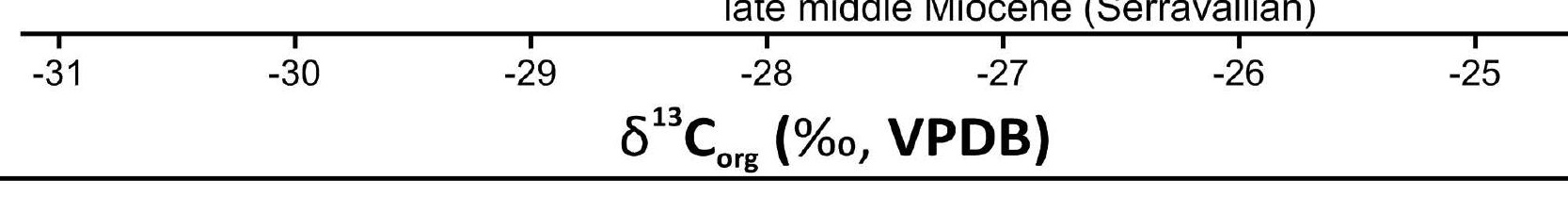


Production \& primary accumulation

Entrapment of insects, leaf imprint, etc.

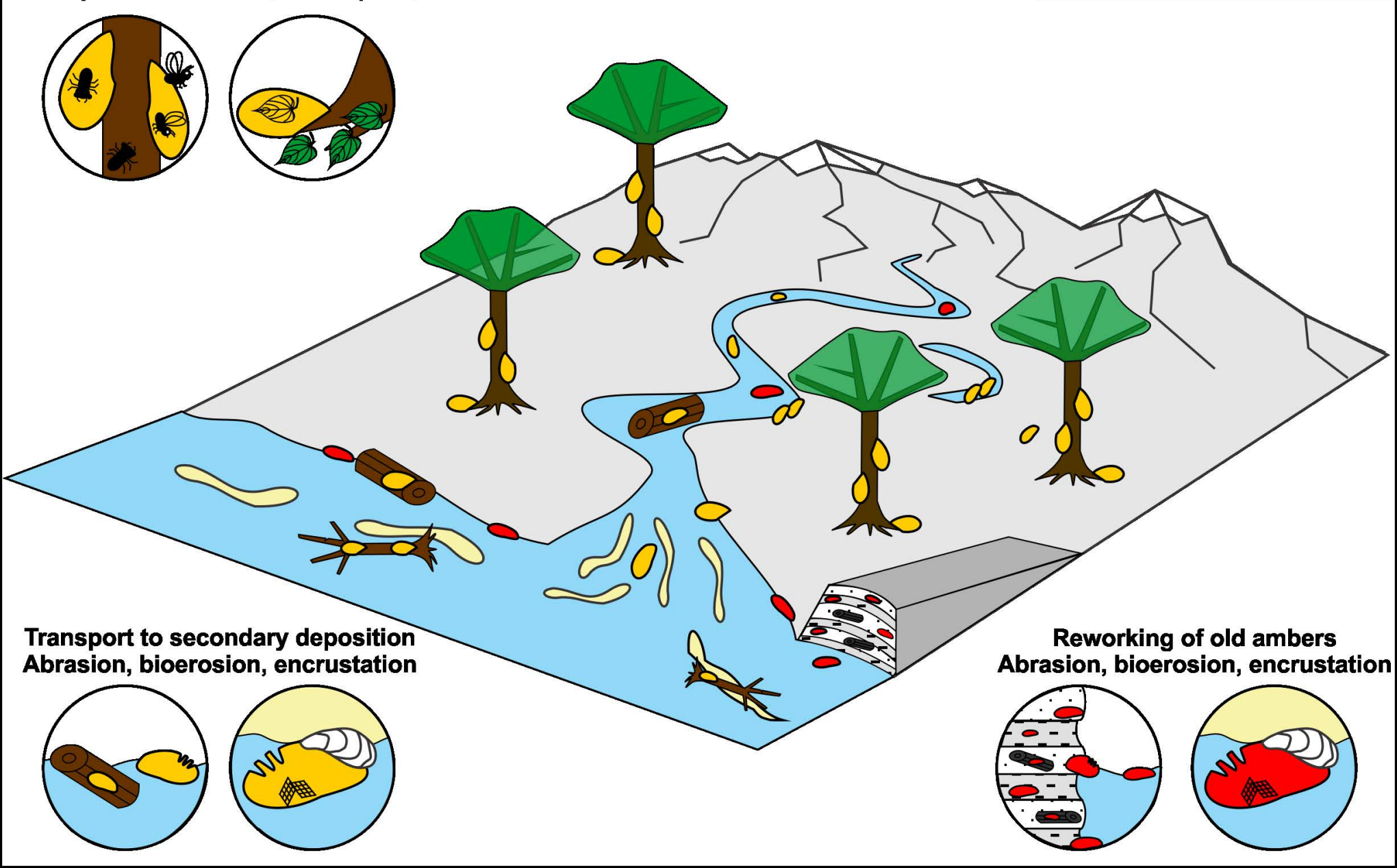




\begin{tabular}{|c|c|c|c|c|c|c|}
\hline Locality & Abr. & Lithostrat. / Geol. Unit & Age & Lithology & FTIR & $\delta^{13} \mathrm{C}$ \\
\hline 1 Mentiri & Mtr & Belait Fm. - Berakas syncline & middle Miocene - Lambiasie \& Cullen, 2013 & silty-clay & 1 & + \\
\hline 2 Subok & Sub & Belait Fm. - Berakas syncline & middle Miocene - Lambiasie \& Cullen, 2013 & clay - 3 outcrops & 2 & + \\
\hline 3 Sungai Akar & SA & Belait Fm. - Berakas syncline & middle Miocene - Lambiasie \& Cullen, 2013 & clay level & 2 & + \\
\hline 4 Kpg. Rimba & KR & Belait Fm. - Berakas syncline & middle Miocene - Lambiasie \& Cullen, 2013 & from the surface of sed rock & 2 & + \\
\hline 5 High Way $84 \mathrm{~km}$ & H84 & Belait Fm. -Belait syncline & late Miocene & clay-silt & 2 & + \\
\hline 6 Water Tower & WT & Belait Fm. -Belait syncline & late Miocene & clay-silt & 2 & + \\
\hline 7 Tanjong Nangka & JT1 & Miri Fm. - Belait syncline & late Miocene - Back et al., 2005 & 3 clay levels sampled & 3 & + \\
\hline 8 Jln. Kecil Paya Teriti & PT & Miri Fm. - Belait syncline & late Miocene & clay & 1 & + \\
\hline $9 \mathrm{Jln}$. Tutong 2 & JT2 & Miri Fm. - Belait syncline & late Miocene & clay & 1 & + \\
\hline $10 \mathrm{Jln}$. Ikas Bandung & IB & Miri Fm. - Belait syncline & late Miocene & clay & 1 & + \\
\hline $11 \mathrm{Jln}$. Tutong 3 & JT3 & Miri Fm. - Belait syncline & late Miocene & clay & 1 & + \\
\hline 12 Maraburong & Mar & Miri Fm. - Belait syncline & late Miocene & clay & 2 & + \\
\hline 13 Miri Hospital Road & Mir & Miri Fm. & middle Miocene - Wannier et al., 2011 & 105 Sand & 1 & + \\
\hline 14 Green House Spg. & GH & Seria Fm. - Belait syncline & late Miocene & clay & 1 & - \\
\hline 15 Keriam & Ker & Seria Fm. - Belait syncline & late Miocene & clay with red beds & 1 & + \\
\hline 16 Ambug Hill & $\mathrm{AH}$ & Seria Fm. - Belait syncline & late Miocene - Kocsis et al., 2018 & from clay, silt and sand units & 15 & + \\
\hline 17 JIn Pak Bidang-1 & JPB1 & Seria Fm. - Belait syncline & late Miocene & clay with sand intercalation & 2 & + \\
\hline 18 Jln Pak Bidang-2 & JPB2 & Seria Fm. - Belait syncline & late Miocene & clay-silt & 1 & + \\
\hline 19 Jln Rumpau Rambai-1 & JRR1 & Seria Fm. - Belait syncline & late Miocene & clay surface & 1 & + \\
\hline 20 Berakas & Ber & Liang Fm. - Berakas syncline & Pliocene - Wannier et al., 2011 & 3 different outcrops - clay-silt & 3 & + \\
\hline 21 Sungai Paku & SP & Berakas syncline & Pleistocene site with re-deposited fossils & in white sand & 1 & + \\
\hline 22 Muara & Mua & Berakas syncline & re-deposited fossils / modern resins & washed up on the beach & 1 & + \\
\hline 23 Penanjong Beach & PB & Belait syncline & re-deposited fossils / modern resins & washed up on the beach & 1 & + \\
\hline
\end{tabular}

\section{Modern-submodern resins}

\begin{tabular}{|c|c|c|c|c|c|c|}
\hline Locality & Abr. & Botanical origin & Region & Origin & FTIR & $\delta^{13} \mathrm{C}$ \\
\hline 1 Tasek Lama & $\mathrm{TL}$ & unknown & Brunei - Muara District & soil covering Belait Fm. & 4 & + \\
\hline 2 Andulau Forest Reserve & AFR & Dipterocarpacea & Belait District & clumps on the forest floor & 3 & + \\
\hline 3 Badas peatswamp forest & Bad & Dipterocarpacea & Belait District & from fallen dead tree & 1 & + \\
\hline 4 Teraja Waterfall walk & Ter & Dipterocarpacea & Belait District & from fallen dead tree & 2 & + \\
\hline 5 Ulu Ulu & Ulu & Dipterocarpacea & Tenburong District & from living tree trunk & 1 & - \\
\hline 6 Sepilok - Sunbear walk - Sabah & Sep & Shorea xanthophylla & Sabah, Malaysia & from living tree trunk & 1 & - \\
\hline 7 Univ. Brunei Darussalam & Ag. & Agathis borneensis & Brunei - Muara District & from living tree trunk & 1 & + \\
\hline
\end{tabular}


Wavenumbers $\left(\mathrm{cm}^{-1}\right)$ at major absorbance bands

\begin{tabular}{|c|c|c|c|c|c|c|c|c|c|}
\hline \multirow{2}{*}{$\begin{array}{l}\text { scaned range } \\
\text { for maxima }\end{array}$} & \multicolumn{4}{|c|}{ Fossil Samples from Borneo $(n=48)$} & \multicolumn{4}{|c|}{ Modern samples from Borneo $(n=12)$} & \multirow{2}{*}{$\begin{array}{l}\text { Agathis } \\
\text { borneensis }\end{array}$} \\
\hline & average & std & $\max$ & $\min$ & average & std & $\max$ & $\min$ & \\
\hline $2961-2945$ & 2957 & 0.6 & 2958 & 2955 & 2956 & 1.8 & 2958 & 2952 & 2945 \\
\hline $2940-2915$ & 2931 & 1.2 & 2934 & 2929 & 2932 & 1.3 & 2935 & 2930 & 2937 \\
\hline \multirow[t]{2}{*}{$2875-2860$} & 2869 & 0.5 & 2869 & 2868 & 2869 & 0.9 & 2871 & 2868 & 2873 \\
\hline & 1730 & & & & & & & & - \\
\hline \multirow[t]{2}{*}{ 1718-1684 } & 1700 & 7.6 & 1716 & 1691 & 1697 & 6.7 & 1715 & 1691 & 1692 \\
\hline & $\sim 1654$ & & & & & & & & $\sim 1645$ \\
\hline $1467-1450$ & 1460 & 3.4 & 1465 & 1456 & 1459 & 3.1 & 1465 & 1456 & 1451 \\
\hline $1390-1378$ & 1384 & 0.2 & 1385 & 1383 & 1384 & 0.8 & 1385 & 1382 & 1385 \\
\hline $1378-1372$ & 1378 & 0.5 & 1378 & 1376 & 1378 & 0.5 & 1378 & 1377 & - \\
\hline $1372-1364$ & 1369 & 1.2 & 1373 & 1368 & 1371 & 2.3 & 1373 & 1369 & - \\
\hline $1325-1300$ & 1315 & 0.5 & 1316 & 1314 & 1314 & 4.3 & 1316 & 1300 & 1316 \\
\hline $1260-1247$ & 1254 & 1.8 & 1256 & 1247 & 1250 & 3.7 & 1255 & 1247 & 1261 \\
\hline $1247-1230$ & 1243 & 1.3 & 1247 & 1239 & 1244 & 1.3 & 1246 & 1241 & 1231 \\
\hline $1195-1170$ & 1180 & 6.7 & 1187 & 1171 & 1186 & 1.5 & 1188 & 1183 & 1177 \\
\hline $1170-1145$ & 1161 & 4.7 & 1171 & 1149 & 1160 & 7.1 & 1171 & 1150 & 1149 \\
\hline $1052-1031$ & 1046 & 1.2 & 1049 & 1044 & 1046 & 2.1 & 1049 & 1044 & 1031 \\
\hline $985-945$ & 973 & 3.8 & 986 & 964 & 978 & 8.0 & 986 & 963 & 974 \\
\hline $891-872$ & 885 & 1.9 & 890 & 882 & 887 & 2.2 & 891 & 883 & 888 \\
\hline $836-815$ & 827 & 1.0 & 828 & 822 & 829 & 2.5 & 836 & 827 & 836 \\
\hline $672-648$ & 663 & 1.9 & 666 & 660 & 662 & 1.5 & 666 & 661 & 672 \\
\hline
\end{tabular}




\begin{tabular}{|c|c|c|c|c|c|c|c|}
\hline \multirow{2}{*}{$\frac{\text { No. }}{1}$} & \multirow{2}{*}{ Locality } & Abr. & \multicolumn{2}{|c|}{$\begin{array}{c}\delta^{13} \mathrm{C} \text { (VPDB) } \\
\text { std. } 0.08\end{array}$} & \multirow{2}{*}{$\begin{array}{r}\text { Average } \\
-26.9\end{array}$} & \multicolumn{2}{|c|}{ Std. $\quad \mathrm{n}$} \\
\hline & & Mtr & -26.74 & & & 0.6 & 4 \\
\hline 2 & Subok & Sub-1 & -27.62 & & late middl & Miocene & \\
\hline 3 & Sungai Akar & SA-1 & -26.23 & & & & \\
\hline 4 & Miri Hospital Road & Mir & -27.17 & & & & \\
\hline 5 & Kpg. Rimba & KR-1 & -26.48 & -26.60 & -27.3 & 1.3 & 11 \\
\hline 6 & High Way $84 \mathrm{~km}$ & $\mathrm{H} 84-2$ & -29.37 & & early late & Miocene & \\
\hline 7 & Water Tower & WT-2 & -28.46 & & & & \\
\hline 8 & Tanjong Nangka & JT1-1 & -26.49 & & & & \\
\hline 9 & Tanjong Nangka & JT1-2 & -29.26 & & & & \\
\hline 10 & Tanjong Nangka & JT1-3 & -26.28 & & & & \\
\hline 11 & Jln. Kecil Paya Teriti & PT & -27.90 & & & & \\
\hline 12 & Jln. Tutong 2 & JT2 & -26.63 & & & & \\
\hline 13 & Jln. Ikas Bandung & IB & -27.35 & & & & \\
\hline 14 & Jln. Tutong 3 & JT3 & -25.80 & & & & \\
\hline 15 & Maraburong & Mar-2 & -26.42 & & & & \\
\hline 16 & Keriam & Ker & -27.03 & & -28.1 & 1.4 & 12 \\
\hline 17 & Ambug Hill & $\mathrm{AH}-1 / 1$ & -30.61 & & latest $\Lambda$ & iocene & \\
\hline 18 & Ambug Hill & Amb-2 & -30.41 & & & & \\
\hline 19 & Ambug Hill & $\mathrm{AH}-3$ & -28.44 & & & & \\
\hline 20 & Ambug Hill & $\mathrm{AH}-4 / 1$ & -27.55 & & & & \\
\hline 21 & Ambug Hill & $\mathrm{AH}-5 / 1$ & -28.93 & & & & \\
\hline 22 & Ambug Hill & $\mathrm{AH}-6$ & -28.36 & & & & \\
\hline 23 & Ambug Hill & $\mathrm{AH}-7$ & -28.56 & & & & \\
\hline 24 & Jln Pak Bidang-1 & JPB1-1 & -27.45 & & & & \\
\hline 25 & Jln Pak Bidang-1 & JPB1-2 & -27.30 & & & & \\
\hline 26 & Jln Pak Bidang-2 & JPB-2 & -26.17 & & & & \\
\hline 27 & Jln Rumpau Rambai-1 & JRR-1L & -26.47 & & & & \\
\hline 28 & Berakas & Ber-1A & -25.59 & -25.61 & -25.4 & 0.2 & $\overline{3}$ \\
\hline 29 & Berakas & Ber-1B & -25.15 & -25.26 & & & \\
\hline 30 & Berakas & Ber-3 & -25.47 & & Plio & ene & \\
\hline 31 & Sungai Paku & SP & -28.75 & & & & \\
\hline 32 & Muara & Mua & -28.58 & & & & \\
\hline \multirow[t]{2}{*}{33} & Penanjong Beach & PB & -28.68 & & -28.7 & 0.1 & \\
\hline & Resin (modern) & & & & & & \\
\hline 35 & Tasek Lama & TL1-1 & -28.48 & & & & \\
\hline 36 & Tasek Lama & TL1-2ex & -31.75 & -31.70 & & & \\
\hline 37 & Tasek Lama & TL1-2int & -32.09 & -32.16 & -30.8 & 2.0 & \\
\hline 38 & Andulau Forest Rv & AFR-1 & -30.29 & -30.31 & & & \\
\hline 39 & Andulau Forest Rv & AFR-2 & -30.92 & & & & \\
\hline 40 & Badas & Bad & -29.37 & -29.47 & & & \\
\hline 41 & Teraja & Ter-ex & -28.61 & & & & \\
\hline 42 & Teraja & Ter-int & -28.20 & & -29.5 & 1.1 & \\
\hline 43 & Univ. Brunei Darussalam & $\mathrm{Ag}$. & -26.57 & & & & \\
\hline
\end{tabular}




\begin{tabular}{|c|c|c|c|c|c|c|c|c|c|c|c|c|c|}
\hline Sample & & $\begin{array}{l}\text { Gross count } \\
\text { rate }(\mathrm{cpm})\end{array}$ & $\begin{array}{l}1 \sigma \\
\text { error }\end{array}$ & $\begin{array}{c}\text { Background } \\
\text { count rate } \\
(\mathrm{cpm}) \\
\end{array}$ & $\begin{array}{l}1 \sigma \\
\text { error }\end{array}$ & $\begin{array}{c}\text { Standard net } \\
\text { count rate } \\
(\mathrm{cpm})\end{array}$ & $\begin{array}{l}1 \sigma \\
\text { error }\end{array}$ & $\begin{array}{c}\text { vs PDB } \\
\delta^{13} \mathrm{C}(\% \circ)\end{array}$ & $\begin{array}{l}\text { vs PDB } \\
1 \sigma \text { error }\end{array}$ & $\begin{array}{l}\mathrm{pMC} \text { value } \\
(\%)\end{array}$ & $\begin{array}{l}1 \sigma \\
\text { error }\end{array}$ & $\begin{array}{c}\text { Age (BP) as } \\
\text { appropriate } \pm 1 \sigma\end{array}$ & $\begin{array}{c}\text { Calibrated calendar } \\
\text { age ranges } \\
\text { (probability - \%) }\end{array}$ \\
\hline \multirow[t]{3}{*}{ Modern cherry tree gum - Hungary } & $\mathrm{HH}-1$ & 7.406 & 0.081 & 0.529 & 0.004 & 6.600 & 0.009 & -23.9 & 0.2 & 103.8 & 1.2 & $-300 \pm 95$ & \\
\hline & & 7.400 & 0.034 & 0.529 & 0.004 & 6.600 & 0.009 & -23.9 & 0.2 & 103.7 & 0.5 & $-290 \pm 40$ & \\
\hline & & & & & & & & & & & & $-295 \pm 52$ & \\
\hline $\begin{array}{l}\text { Modern Diptero resin - } \\
\text { Andulau Forest Reserve }\end{array}$ & AFR-1 & 7.307 & 0.030 & 0.529 & 0.004 & 6.600 & 0.009 & -30.5 & 0.2 & 104.0 & 0.5 & $-315 \pm 40$ & \\
\hline Resin from soil - Tasek Lama & TL1-1 & 6.966 & 0.029 & 0.599 & 0.004 & 8.764 & 0.011 & -29.5 & 0.2 & 73.4 & 0.4 & $2480 \pm 40$ & $\begin{array}{c}775-472 \mathrm{BC} \\
(96 \%)\end{array}$ \\
\hline \multirow[t]{4}{*}{ Resin from soil - Tasek Lama } & TL1-2 & 8.661 & 0.030 & 0.599 & 0.004 & 8.764 & 0.011 & -32.08 & 0.2 & 93.5 & 0.5 & $545 \pm 30$ & \\
\hline & & 6.575 & 0.026 & 0.529 & 0.004 & 6.600 & 0.009 & -32.08 & 0.2 & 93.1 & 0.4 & $580 \pm 40$ & \\
\hline & & 5.054 & 0.024 & 0.525 & 0.004 & 4.920 & 0.009 & -32.07 & 0.2 & 93.8 & 0.5 & $510 \pm 45$ & \\
\hline & & & & & & & & & & \multicolumn{2}{|r|}{ AV. } & $545 \pm 35$ & $\begin{array}{c}1391-1430 \text { AD } \\
(72 \%)\end{array}$ \\
\hline \multirow[t]{2}{*}{ Subok - Middle Miocene } & Sub-1 & 0.598 & 0.007 & 0.599 & 0.004 & 8.764 & 0.011 & -27.83 & 0.2 & 0.0 & 0.1 & nan & \\
\hline & & 0.528 & 0.007 & 0.529 & 0.004 & 6.600 & 0.009 & -27.83 & 0.2 & 0.0 & 0.1 & nan & \\
\hline $\begin{array}{l}\text { Ambug Hill - fossil wood } \\
\text { Late Miocene }\end{array}$ & Amb-W & 0.573 & 0.007 & 0.599 & 0.004 & 8.761 & 0.011 & -27.3 & 0.2 & -0.3 & 0.1 & nan & \\
\hline
\end{tabular}




\begin{tabular}{|c|c|c|c|c|c|c|c|c|c|c|}
\hline \multirow[t]{2}{*}{ Sample } & \multirow[t]{2}{*}{ Color } & \multirow[t]{2}{*}{ Trancparency } & \multicolumn{3}{|c|}{ Heat test with hot needle } & \multirow{2}{*}{\begin{tabular}{|c|} 
Odour \\
natural
\end{tabular}} & \multirow[t]{2}{*}{ UV } & \multirow{2}{*}{$\begin{array}{l}\text { Flotation } \\
\text { seawater }\end{array}$} & \multicolumn{2}{|r|}{ Acetone } \\
\hline & & & melting & smoke & odor & & & & 5 mins & overnight \\
\hline 1 Sub-1 & black/orange & + & easy & white & resinous & resinous & +++ & - & - & L: no color, S: whitish cover \\
\hline $2 \mathrm{SA}$ & black/orange & + & easy & white & resinous & resinous & +++ & - & - & L: yellow, S: white cover \\
\hline 3 Miri & black/orange & partially opaque & easy & white & resinous & resinous & ++ & - & - & L: no color, S: thin whitish cover \\
\hline 4 JT1-1 & black/orange & + & easy & white & resinous & resinous & + & - & - & L: no color, S: thin whitish cover \\
\hline 5 Ker & black/orange & + & easy & white & resinous & resinous & ++ & - & - & L: very minor discoloring, S: white cover \\
\hline $6 \mathrm{AH}-3$ & black & opaque & easy -quick & white & acrid & resinous & $+/-$ & - & - & L: minor discoloring, S: grey-brown cover \\
\hline 7 Amb-2 & orange & opaque & easy & white & resinous & resinous & $++/-$ & + & L: yellowish & L: yellow, S: white patches cover \\
\hline $8 \mathrm{AH} 1-1$ & orange & + & easy & white & resinous & resinous & + & + & - & L: very minor discoloring, S: small white dots \& white cover \\
\hline 9 Ber-1 & yellow/green & + & easy & white & resinous & resinous & ++ & $+/-$ & S: turned white & L: slightly yellowish, S: completely white \\
\hline 10 TL1-2 & orange & partially opaque / transluscent & easy -quick & white & lemony tinge & resinous & + & + & L: yellowish & L: yellow, S: white-grey - disintegrated \\
\hline 11 AFR-1 & brown & opaque / transluscent & easy -quick & white & lemony tinge & resinous & + & - & S: turned white & L: very minor discoloring, S: white cover, disintegrated \\
\hline 12 Baltic & orange & + & hard & no & resinous & - & + & - & - & L: slightly yellowish, S: no color change \\
\hline
\end{tabular}

